\title{
Enhancements to the FAST-MAC Circulation Control Model and Recent High-Reynolds Number Testing in the National Transonic Facility
}

\author{
William E. Milholen, II ${ }^{1}$, Gregory S. Jones ${ }^{2}$, David T. Chan ${ }^{3}$, Scott L. Goodliff ${ }^{4}$, \\ Scott G. Anders ${ }^{5}$, Latunia P. Melton ${ }^{6}$, Melissa B. Carter ${ }^{7}$, Brian G. Allan ${ }^{8}$, and Francis J. Capone ${ }^{9}$ \\ NASA Langley Research Center, Hampton, VA, 23681
}

\begin{abstract}
A second wind tunnel test of the FAST-MAC circulation control model was recently completed in the National Transonic Facility at the NASA Langley Research Center. The model was equipped with four onboard flow control valves allowing independent control of the circulation control plenums, which were directed over a $15 \%$ chord simple-hinged flap. The model was configured for low-speed high-lift testing with flap deflections of 30 and $\mathbf{6 0}$ degrees, along with the transonic cruise configuration with zero degree flap deflection. Testing was again conducted over a wide range of Mach numbers up to 0.88 , and Reynolds numbers up to 30 million based on the mean chord. The first wind tunnel test had poor transonic force and moment data repeatability at mild cryogenic conditions due to inadequate thermal conditioning of the balance. The second test demonstrated that an improvement to the balance heating system significantly improved the transonic data repeatability, but also indicated further improvements are still needed. The low-speed highlift performance of the model was improved by testing various blowing slot heights, and the circulation control was again demonstrated to be effective in re-attaching the flow over the wing at off-design transonic conditions. A new tailored spanwise blowing technique was also demonstrated to be effective at transonic conditions with the benefit of reduced mass flow requirements.
\end{abstract}

\section{Nomenclature}

$\mathrm{AF}=$ balance axial force, lbs.

$\mathrm{b}$ = wing span

$\mathrm{c} \quad=$ local wing chord

$\mathrm{C}_{\mathrm{D}}=$ drag coefficient

$\mathrm{C}_{\mathrm{L}}=$ lift coefficient

$\mathrm{C}_{\mathrm{m}}=$ pitching moment coefficient

$\mathrm{C}_{\mathrm{p}}=$ surface pressure coefficient

$\mathrm{C}_{\mathrm{p}} *$ = sonic value of $\mathrm{C}_{\mathrm{p}}$

$$
\begin{aligned}
& \mathrm{T} \quad=\text { temperature } \\
& \mathrm{U}_{\text {jet }}=\text { velocity at jet exit } \\
& \mathrm{x}, \mathrm{y}, \mathrm{z}=\text { Cartesian coordinate system } \\
& \mathrm{YM}=\text { balance yawing moment, inch-lbs. } \\
& \alpha \quad=\text { angle of attack } \\
& \delta_{\mathrm{f}}=\text { flap deflection angle } \\
& \eta \quad=\text { non-dimensional semi-span location }
\end{aligned}
$$

\footnotetext{
${ }^{1}$ Research Engineer, Configuration Aerodynamics Branch, Mail Stop 499, AIAA Senior Member

${ }^{2}$ Research Engineer, Flow Physics and Control Branch, Mail Stop 170, AIAA Senior Member

${ }^{3}$ Research Engineer, Configuration Aerodynamics Branch, Mail Stop 499, AIAA Member

${ }^{4}$ Test Engineer, Jacobs Technology, Inc., Mail Stop 267, AIAA Senior Member

${ }^{5}$ Research Engineer, Revolutionary Aviation Technologies Branch, Mail Stop 207, AIAA Senior Member

${ }^{6}$ Research Engineer, Flow Physics and Control Branch, Mail Stop 170, AIAA Associate Fellow

${ }^{7}$ Research Engineer, Configuration Aerodynamics Branch, Mail Stop 499, AIAA Senior Member

${ }^{8}$ Research Engineer, Flow Physics and Control Branch, Mail Stop 170, AIAA Senior Member

${ }^{9}$ Research Engineer, AMS, Mail Stop 499, AIAA Senior Member
} 
$\mathrm{C}_{\mu}=$ momentum coefficient

$\mathrm{h}=$ blowing slot height

$\mathrm{NF}=$ balance normal force, lbs.

$\mathrm{M}=$ local value of Mach number

$M_{\infty}=$ freestream Mach number

$\dot{m}=$ mass flow

$\mathrm{NPR}=$ nozzle pressure ratio, $\left(p_{o}\right)_{j e t} / p_{\infty}$

$\mathrm{p}=$ pressure

$\mathrm{PM}=$ balance pitching moment, inch-lbs.

$\mathrm{q}_{\infty}=$ freestream dynamic pressure

$\mathrm{Re}=$ Reynolds number based on mean aerodynamic chord

$\mathrm{RM}=$ balance rolling moment, inch-lbs.

$\mathrm{S}$ = wing reference area

$$
\begin{aligned}
& \begin{array}{l}
\sigma \quad=\text { standard deviation } \\
\rho=\text { density }
\end{array} \\
& \text { subscripts } \\
& \text { jet } \quad=\text { jet exit location } \\
& 0 \quad=\text { stagnation quantity } \\
& \infty \quad=\text { freestream quantity }
\end{aligned}
$$$$
\text { I. Introduction }
$$

Many of the advanced aircraft being designed today utilize active flow control systems that closely integrate with both the engine and airframe ${ }^{1,2,3,4}$. Cruise efficiency, community noise, and runway independence can no longer be optimized independently because of the close coupling of the engine, airframe, and wing. Evaluating the benefits of active flow control systems on scaled wind tunnel models requires added attention to detail. Not only does the outer mold line of the model need to accurately represent the proposed flight vehicle, but also the intricate details of the flow control system ${ }^{5}$. If the flow control system adds or removes a net mass to the flow field, it is necessary to accurately characterize the mass flow and document the fluid conditions at the relevant model interface locations. It is desirable that the wind tunnel testing be conducted at Reynolds numbers that are representative of flight conditions, to document the appropriate scaling parameters, and ensure the active flow control technique is properly scaled to the flight vehicle. This paper focuses on the second active flow control experiment conducted in the National Transonic Facility (NTF) at the NASA Langley Research Center, Figure 1. The Fundamental Aerodynamics Subsonic/Transonic-Modular Active Control (FAST-MAC) model was again used to test circulation control concepts

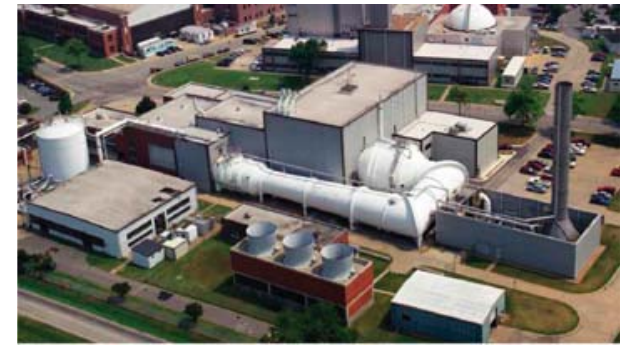

Figure 1: Aerial view of the NTF.

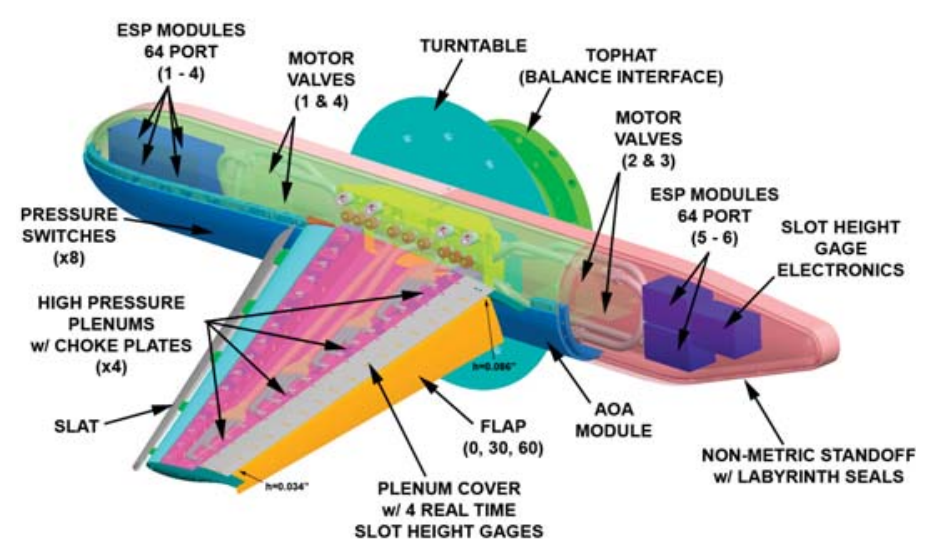

Figure 2: Cutaway view of the FAST-MAC model, in high-lift mode, highlighting multiple internal flow paths. 
at realistic flight Reynolds numbers at both low-speed and transonic cruise conditions, building upon the successes of the first test entry (NTF Test 195) ${ }^{6}$.

Circulation control techniques have experienced a resurgence recently, with many research efforts focusing on developing databases for CFD validation ${ }^{7,8,9,10,11,12}$, as unreliable predictions have been a barrier to applying the techniques to aircraft. As with most publically available active flow control datasets, one shortfall remains the lack of Reynolds number scaling data, which could limit the application of the technique to flight conditions. The FAST-MAC model, depicted in Figure 2 in the high-lift mode, was developed to allow active flow control techniques such as circulation control to be tested at realistic flight Reynolds numbers in the NTF. The model is modular, allowing nearly all wing components to be replaced, and is well suited for future testing of other flow control concepts. Even though the wing has a moderate aspect ratio, the wing design represents the state-of-the-art in transonic wing design ${ }^{13,14}$ and is an open geometry that can be distributed to the research community. The model is also unique in that it will allow circulation control strategies to be evaluated at transonic Mach numbers, where little research has been published ${ }^{15}$.

In the low-speed high-lift mode, the circulation control is applied as shown in Figure 3, where a high momentum jet from a blowing slot is directed over a simple short-chord hinged flap ${ }^{16}$. The jet flow from the blowing slot is typically characterized by the nondimensional blowing coefficient $\mathrm{C}_{\mu}$, defined by equation 1 . The non-dimensional slot height, h/c, and the plenum stagnation pressure are the key parameters defining the maximum jet velocity ${ }^{17}, \mathrm{U}_{\text {JET }}$. The model was designed to allow the circulation control to be manipulated by four independent plenums across the span of the wing, each with a computer-controlled valve located in the fuselage. A unique suite of instrumentation was developed to document the

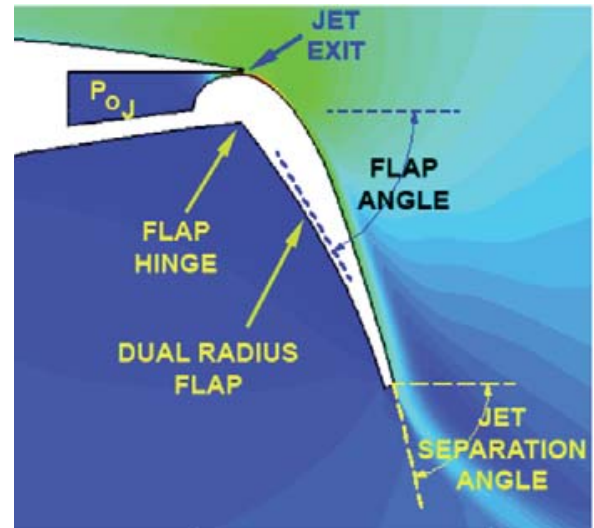

Figure 3: Circulation control blowing slot nomenclature. internal and external flow features of the model.

$$
C_{\mu}=\frac{\text { Thrust }}{q_{\infty} S}=\frac{2 h b_{j e t}}{c b} \frac{\rho_{j e t}}{\rho_{\infty}} \frac{U_{j e t}^{2}}{U_{\infty}^{2}}=\frac{\dot{m} U_{j e t}}{q_{\infty} S}
$$

The successes of the first test of the FAST-MAC model, Test 195, were documented in a recent paper $^{6}$. That test made considerable progress in developing active flow control testing in the NTF, and demonstrated the ability of circulation control to improve the off-design transonic performance of the model. At the time of that report, the force and moment data had not been corrected to account for biases created by the variable static pressure in the concentric bellows, which bridged the balance to deliver the high-pressure air used by the circulation control blowing system. The subsequent post-test system-level pressure and temperature tare calibration for the balance and bellows was performed ${ }^{22}$, and the force and moment data analysis was conducted. 
The results of this analysis revealed a serious short coming of the initial testing technique, in that the balance temperature could not be adequately controlled during transonic testing at the mild cryogenic testing temperature of $-50^{\circ} \mathrm{F}$. The Balance Cavity Recirculation System (BCRS), which will be discussed below, had been modified when the high-pressure supply lines were routed through the center of the balance. The net result was that inadequate convective heat transfer was supplied to the balance housing, and the balance temperature drifted well outside of the region of post-test correctability. This is graphically illustrated in Figure 4 which compares
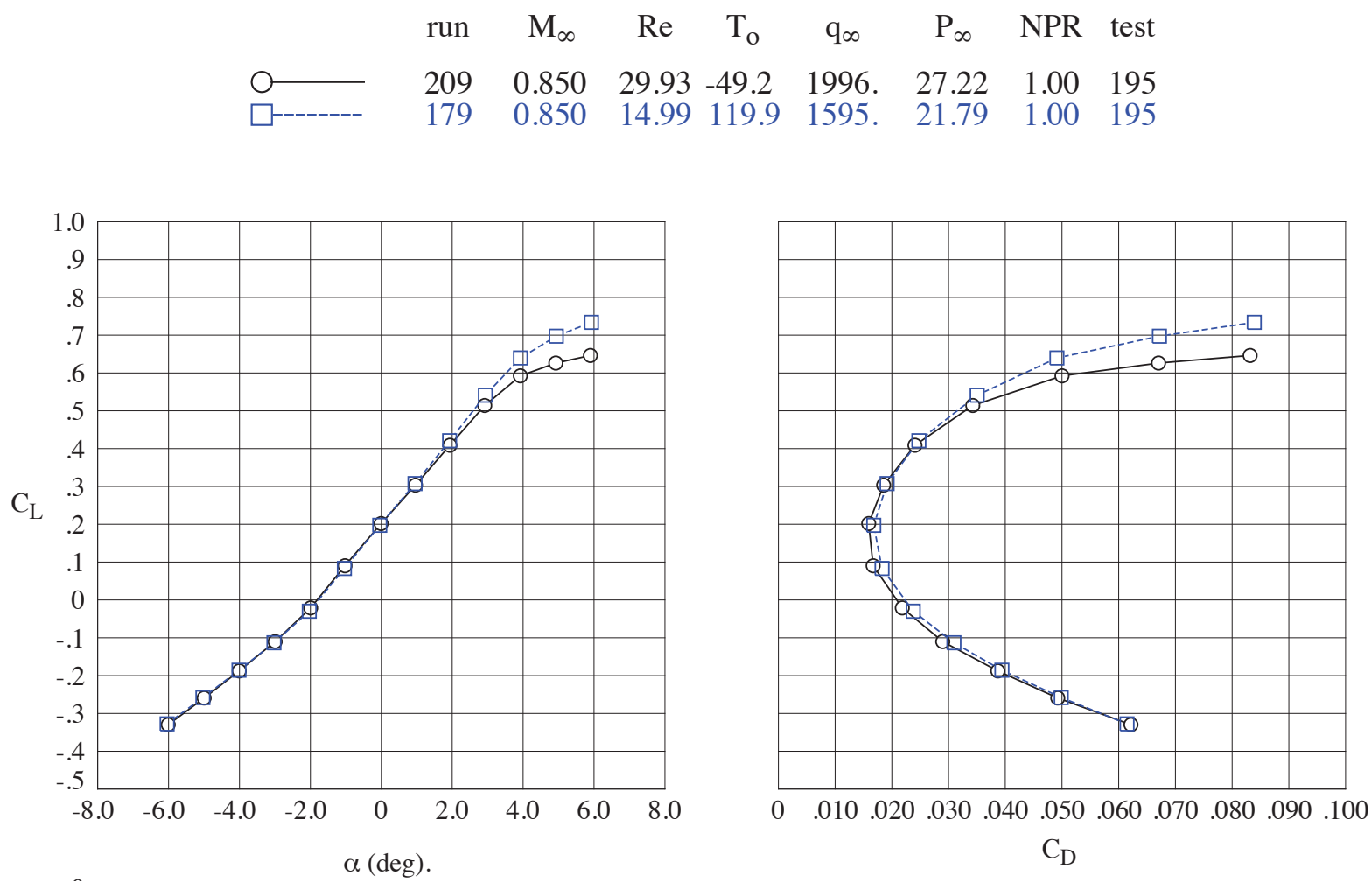

Figure 4: Effect of tunnel temperature on lift and drag coefficient data from Test $195\left(\mathrm{M}_{s}=0.85, \mathrm{C}_{\mu}=0.0\right)$.

lift and drag coefficient data from Test 195 for a $120^{\circ} \mathrm{F}$ and $-50^{\circ} \mathrm{F}$ run at $\mathrm{M}_{\infty}=0.85$ with noblowing through the circulation control system. Note the degradation of the shapes of each curve. Generally such a change in tunnel conditions would be expected to produce small changes in each curve for a well-designed configuration. The cryogenic balance data from Test 195 was clearly not acceptable.

The second test of the model, Test 213, was already being planned and was reformulated to address the shortfalls of Test 195. Several improvements to the internal flow path of the FASTMAC model were performed and are reported in a companion paper ${ }^{18}$. The BCRS was improved to address the issues associated with balance temperature that was experienced in Test 195, and more repeat runs were included during the transonic portion of the testing to emphasize data repeatability. The flow physics objectives of the transonic portion of the test were similar to those of Test 195, but included a new tailored spanwise blowing distribution developed using CFD analysis. The low-speed high-lift testing was expanded to document the influence of 
several slot height configurations, and a new $30^{\circ}$ trailing edge flap deflection was tested. Lastly, the concentric bellows used in Test 195 were replaced with a new Pressure Interface Part (PIP) developed by the NASA National Force Measurement Technology Capability group. The PIP and the new system-level pressure tare calibration for the balance will be discussed in detail.

\section{Experimental Setup}

\section{A. Model Description}

The FAST-MAC model shown in Figure 5 has a modern supercritical wing and was designed to become an NTF standard for evaluating performance characteristics of integrated active flow control and propulsion systems. The outer mold line of the model was designed for a cruise Mach number of 0.85 , a lift coefficient of 0.50 , at a Reynolds number based on mean aerodynamic chord of $30 \times 10^{6}$. A tangential blowing slot is located at the $85 \%$ chord location on the upper surface, and is directed over a $15 \%$ chord simple hinged flap for both the cruise and high-lift configurations ${ }^{13}$. For transonic testing, the nondimensional blowing slot height was set to $\mathrm{h} / \mathrm{c}=0.0021$. The wing has an aspect ratio of 5.0, taper ratio of 0.40 , a leading edge sweep of $30^{\circ}$, zero dihedral, a reference area of $6.06 \mathrm{ft}^{2}$, and a mean aerodynamic chord of 19.4 inches. The generic fuselage is comprised of circular cross sections with a maximum width of 5.0 inches, and a length of 82.0 inches. The wing is mounted in the mid-fuselage position to simplify the routing of the high-pressure air supply lines. The model is offset from the tunnel sidewall using a 2.0-inch non-metric standoff ${ }^{19}$, which has a profile shape identical to that of the fuselage centerline. Figure 6 shows a photograph of the model installed in the test section.

Figure 7 shows a CAD rendering of the model configured for low-speed high-lift testing with a $60^{\circ}$ deflection of the hinged trailing-edge flap. This configuration was tested with the slot height to chord ratio of $\mathrm{h} / \mathrm{c}=0.0032$ used in Test 195 , and a smaller setting of $\mathrm{h} / \mathrm{c}=0.0021$. A new intermediate $30^{\circ}$ trailing edge flap configuration was also tested with the $\mathrm{h} / \mathrm{c}=0.0021$ setting, and a new constant slot height with the same open area. The main-wing leading edge is protected from premature flow separation by a leading edge slat with an average deflection angle of $25^{\circ}$ with respect to the cruise leading edge $^{6}$.

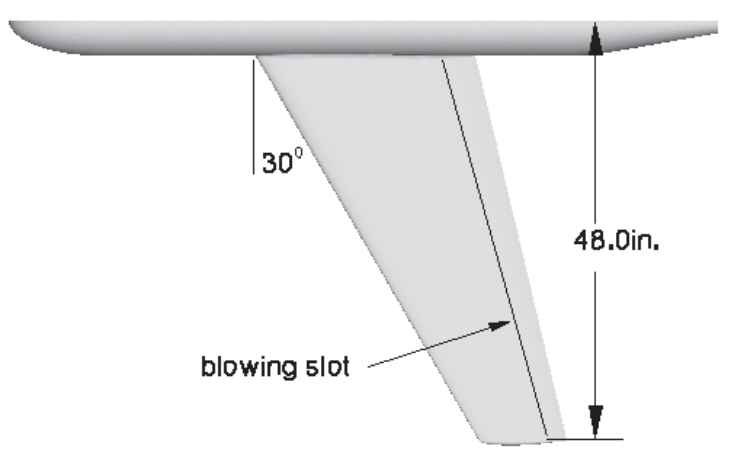

Figure 5: Planform view of the FAST-MAC semispan model.

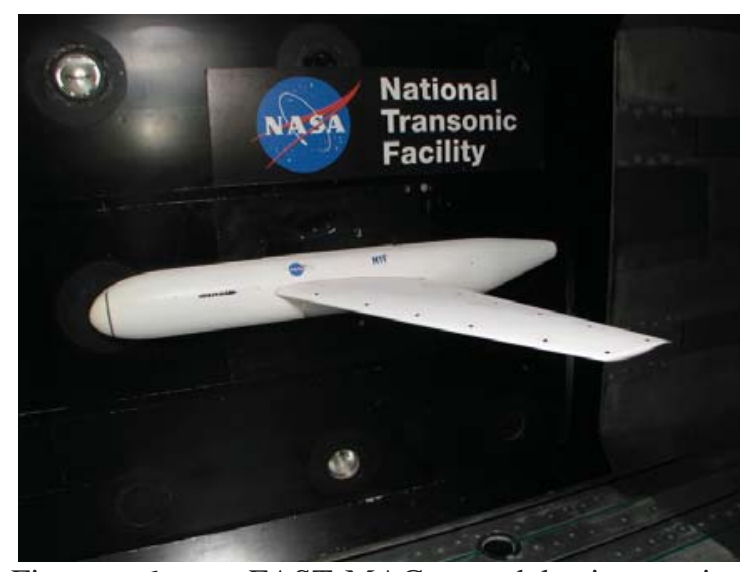

Figure 6: FAST-MAC model in cruise configuration mounted on the sidewall in the NTF.

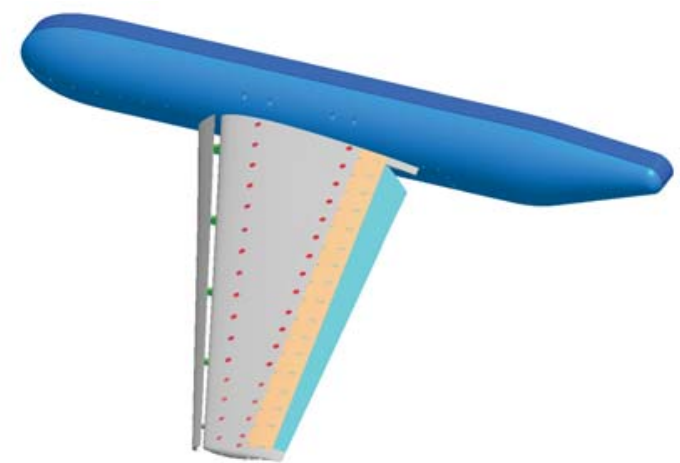

Figure 7: FAST-MAC model configured for highlift testing with $60^{\circ}$ flap. 
The FAST-MAC model utilized four flow paths to achieve independent lift and thrust performance along the span of the circulation control flap, as shown previously in Figure 2. Each plenum section was fed by a flow control valve located in the fuselage via a rapid diffuser located in the wing box, where the outboard plenum is shown in Figure 8. The diffuser is used to subdivide the incoming flow to the plenum, allowing it to be supplied at four evenly spaced spanwise locations. A new set of approximately $17 \%$ open area orifice plates were designed and bench tested prior to the test ${ }^{18}$, to remedy the poor performance of the choke plates used in Test $195^{6}$. The orifice plates are used to improve flow uniformity, and provide a means for calibrating the mass flow in each independent plenum. The flow then enters the aft plenum region of the model, where the upper plenum cover is supported by the streamlined standoffs, which are used to set the blowing slot height. A nominal cross sectional view of the aft plenum with the cut taken between the standoffs is shown in Figure 9 for the $60^{\circ}$ flap deflection. At the slot exit, this corresponds to a 6 to 1 contraction ratio for the non-dimensional slot height of $\mathrm{h} / \mathrm{c}=0.0032$. For the value of $h / c=0.0021$, this gives a slot exit contraction ratio of 12 to 1 .

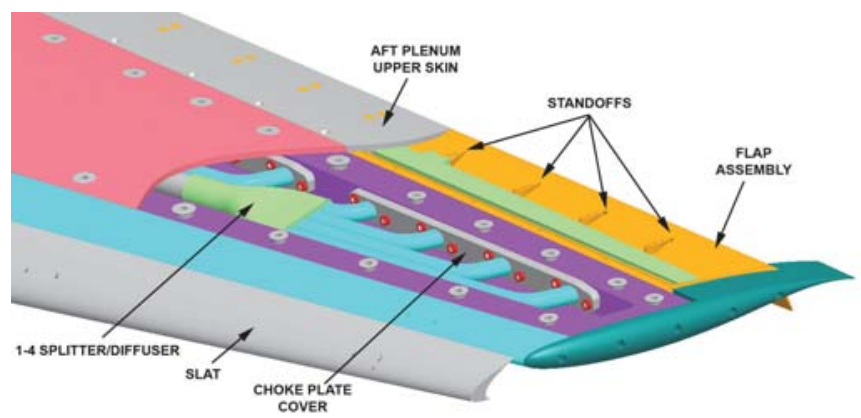

Figure 8: Cutaway sketch of the outboard plenum highlighting the flow path.

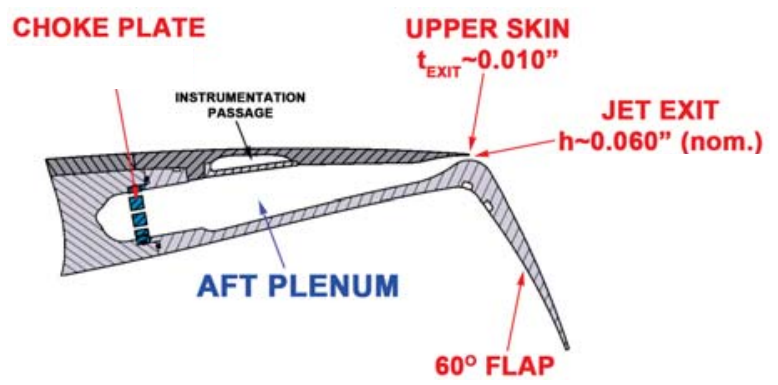

Figure 9: Cross sectional sketch of the aft plenum region on the FAST-MAC model.

\section{B. NTF-117S Balance and Pressure Tare Calibration}

The NTF-117S balance ${ }^{20}$ was again used to measure the forces and moments on the model, and Figure 10 shows a schematic of a semi-span model mounted to the balance via the Sidewall Model Support System (SMSS). The dual flow high-pressure air station ${ }^{21}$ at the NTF is coupled to the SMSS by the two independently controlled airlines passing through the center of the balance, which bridge the balance to the model using the new PIP. The BCRS system is annotated, showing the closed loop mode used during Test 213. During Test 195, the return leg shown near the balance was left open inside the climate controlled SMSS housing, which contributed to the inability of the system to maintain the balance temperature. 


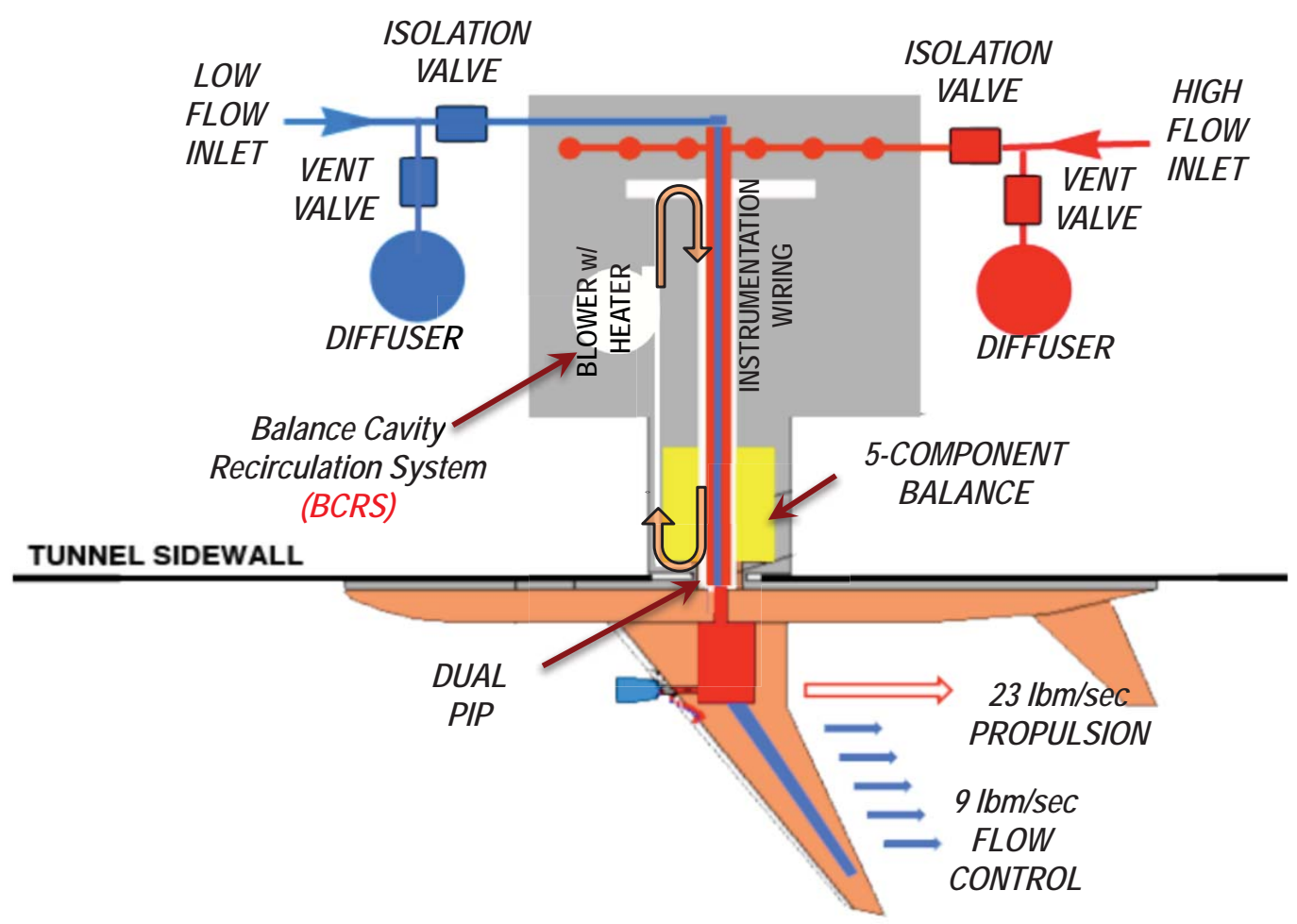

Figure 10: Diagram of high-pressure air routing to a semi-span model mounted on the sidewall of the NTF.

A cross-sectional sketch of the concentric bellows used in Test 195 is shown in Figure 11, while Figure 12 shows a view of the outer portion of the new PIP. A new pressure tare calibration for the PIP was performed prior to the test, and was completed with the balance installed in the SMSS housing. It is thus considered a system-level calibration as it takes into account the actual mounting hardware used in the wind tunnel, and the PIP pressure and temperature that influence the stiffness of the piping. Table 1 presents the results of the systemlevel calibration obtained using the same methodology in Reference 22. The static pressure and temperature of the PIP were varied while the balance system was calibrated. The results are presented both as a percentage of full-scale load accuracy, as well as in Engineering

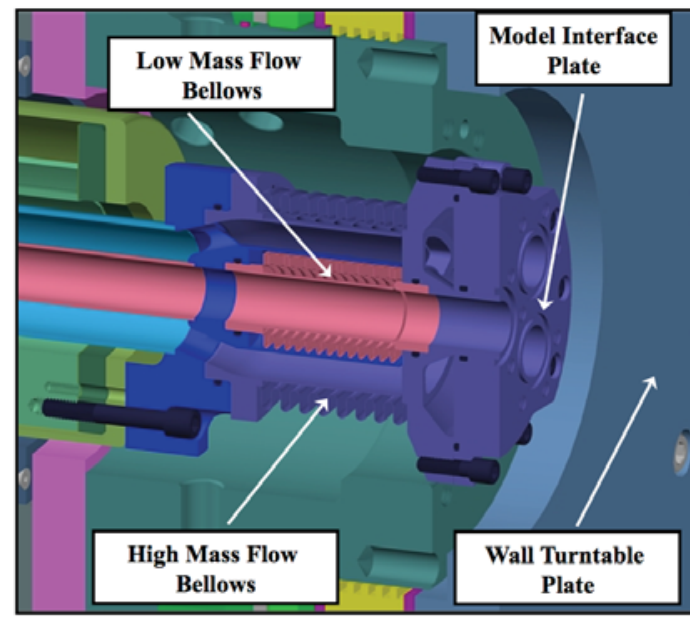

Figure 11: Cross sectional view of the bellows at the model attachment location (Test 195).

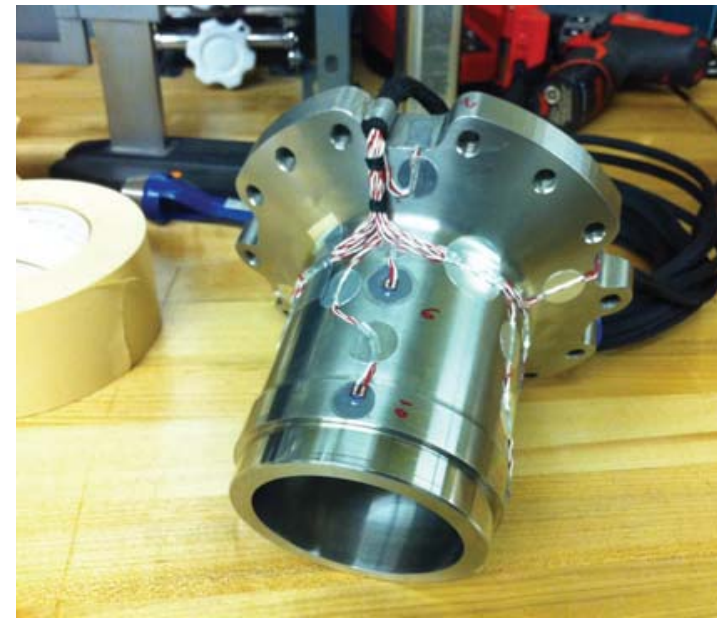

Figure 12: Outer portion of the new PIP hardware (Test 213). 
Units (EU) of pounds or inch-pounds. The right side of the table converts the system-level balance accuracies to the anticipated accuracy of the related aerodynamic coefficients for the FAST-MAC model in the balance axis system. Thus the expected axial coefficient repeatability at $\mathrm{M}_{\infty}=0.85$ and $\mathrm{Re}=30 \times 10^{6}$ for the FAST-MAC model would be \pm 0.0006 . The new PIP did significantly improve the system-level accuracy of the balance as compared to the concentric bellows system used in Test 195, with the comparison shown for each balance component in

Table 1: System -level balance accuracy results for the NTF-117S balance pressure tare calibration using the new PIP (coefficient accuracies based on FAST-MAC model dimensions).

\begin{tabular}{|c|c|c|c|c|c|c|c|}
\cline { 4 - 8 } & \multicolumn{4}{c|}{ Accuracy Coefficient } \\
\hline $\begin{array}{c}\text { Balance } \\
\text { Component }\end{array}$ & $\begin{array}{c}\text { Calibration } \\
\text { Load Range }\end{array}$ & $\begin{array}{c}\text { Accuracy } \\
\text { \%F.S. }\end{array}$ & Accuracy EU & $\begin{array}{c}\mathbf{M}_{\infty}=\mathbf{0 . 2 0} \\
\mathbf{R e}=\mathbf{5} \mathbf{M}\end{array}$ & $\begin{array}{c}\mathbf{M}_{\infty}=\mathbf{0 . 2 0} \\
\mathbf{R e}=\mathbf{1 5} \mathbf{M}\end{array}$ & $\begin{array}{c}\mathbf{M}_{\infty}=\mathbf{0 . 8 5} \\
\mathbf{R e}=\mathbf{1 0 M}\end{array}$ & $\begin{array}{c}\mathbf{M}_{\infty}=\mathbf{0 . 8 5} \\
\mathbf{R e}=\mathbf{3 0 M}\end{array}$ \\
\hline Axial (Ibs) & 1800 & 0.432 & 7.78 & 0.0096 & 0.0046 & 0.0012 & 0.0006 \\
\hline Normal (Ibs) & 12000 & 0.136 & 16.32 & 0.0201 & 0.0096 & 0.0025 & 0.0013 \\
\hline Pitch (in-lbs) & 90000 & 0.072 & 64.80 & 0.0041 & 0.0020 & 0.0005 & 0.0003 \\
\hline Roll (in-lbs) & 670000 & 0.063 & 422.10 & 0.0108 & 0.0052 & 0.0014 & 0.0007 \\
\hline Yaw (in-lbs) & 110000 & 0.182 & 200.20 & 0.0051 & 0.0025 & 0.0006 & 0.0003 \\
\hline
\end{tabular}

Table 2: Improvement of the system -level balance accuracy results for the NTF-117S balance pressure tare calibration using the new PIP as compared to the bellows(Engineering Units in pounds, or inch-pounds).

\begin{tabular}{|l|l|l|l|l|l|l|}
\hline & & AF & NF & PM & RM & YM \\
\hline \multirow{2}{*}{$\begin{array}{l}\text { T195 Calibration } \\
\text { Convoluted Bellows) }\end{array}$} & 2-sigma, \% Full-Scale & 0.538 & 0.256 & 0.148 & 0.163 & 0.196 \\
\cline { 2 - 7 } & 2-sigma, EU Load & 9.684 & 30.72 & 133.2 & 1092.1 & 215.6 \\
\hline $\begin{array}{l}\text { T213 Calibration } \\
(P I P)\end{array}$ & 2-sigma, \% Full-Scale & 0.432 & 0.136 & 0.072 & 0.063 & 0.182 \\
\cline { 2 - 7 } & 2-sigma, EU Load & 7.776 & 16.32 & 64.8 & 422.1 & 200.2 \\
\hline \multicolumn{2}{|c|}{ Improvements } & $19.70 \%$ & $46.90 \%$ & $51.30 \%$ & $61.30 \%$ & $7.10 \%$ \\
\hline
\end{tabular}

Table 2. The overall influence of the PIP on the balance sensitivity was found to be less than 1\%. These improvements were the primary reason that the PIP was used in Test 213. The force and moment data for Test 213 have been corrected for the PIP pressure and temperature by applying the system-level static pressure tare calibration developed for the new PIP system.

\section{Test Conditions}

The low-speed high-lift portion of the testing was primarily conducted at a freestream Mach number of 0.20 , while a limited dataset was obtained at $\mathbf{M}_{\infty}=0.10$. The high-lift Reynolds number range based on the mean chord was 5.0,10.0 and 15.0 million. The angle-of-attack was varied from $-20^{\circ}$ to $27^{\circ}$. The transonic portion of the test focused on Mach numbers from 0.85 to 0.88. The Reynolds numbers based on the mean chord were 10.0, 15.0, and 30 million. The tunnel stagnation temperature range for both portions of the experiment was $-50^{\circ} \mathrm{F}$ to $120^{\circ} \mathrm{F}$. Data was also obtained to characterize the model deformations using the Video Model Deformation system, however this data will not be presented. 


\section{Results}

The performance of the FAST-MAC model is best described as a function of the momentum coefficient, $\mathrm{C} \mu$. However, the compressible characteristics that can occur at the blowing slot are related to NPR value. In general the test was implemented by varying NPR because it was more time consuming to set a specific value of $\mathrm{C} \mu$. An extensive set of tunnel-off thrust calibrations were performed throughout the test to develop a thrust removal strategy to properly document the effect of the circulation control blowing on the drag characteristics of the model, which is of particular importance in the transonic regime. At this time, the thrust removal technique has not been validated, and the data presented below still includes the thrust from the blowing slot.

\section{A. Low-Speed High-Lift Testing, $60^{\circ}$ Flap}

The effect of blowing slot height on the lift performance of the FAST-MAC configuration is demonstrated by the NPR sweep in Figure 13 for $M_{\infty}=0.20, \alpha=0^{\circ}$ and $\mathrm{Re}=10 \times 10^{6}$. The original slot height to chord ratio, $\mathrm{h} / \mathrm{c}=0.0032$ tested during Test 195 was found to develop an external supersonic flow near NPR $=1.50$, followed by premature loss of lift ${ }^{6}$. This behavior was again verified in the current experiment as shown in this comparison. The smaller slot height to chord ratio, $\mathrm{h} / \mathrm{c}=0.0021$ was found to delay the shock induced flow separation until $\mathrm{NPR}=1.80$, improving the lift performance of the flap by $28.75 \%$. Note that both configurations achieve the maximum lift coefficient near the value of $\mathrm{C} \mu=0.10$. The data from the smaller slot height to chord ratio follows the classic trend of two distinct slopes: the initial rapid increase in lift coefficient due to attaching the flow over the flap (separation control); followed by the continued
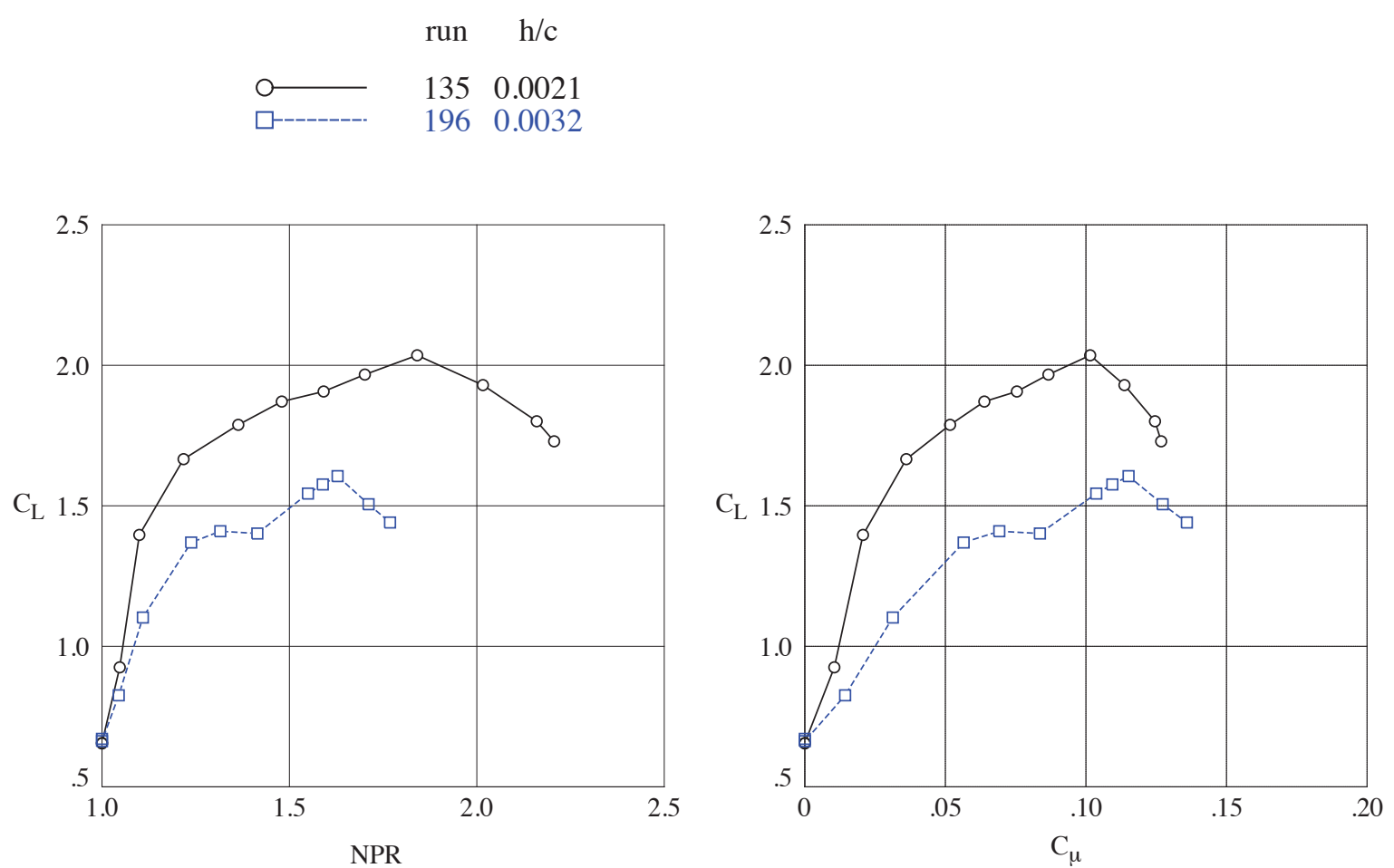

Figure 13: Effect of blowing slot height on FAST-MAC high-lift performance of the $60^{\circ}$ flap $\left(M_{s}=0.20, \alpha=0^{\circ} \cdot \operatorname{Re}=10 \times 10^{6}\right)$. 
increase in lift as the blowing affects the off-body flap wake trajectory (super circulation). The beginning of the super-circulation regime for the $\mathrm{h} / \mathrm{c}=0.0021$ configuration occurs at $C \mu \sim 0.03$. Additional data comparisons at $\mathrm{M}_{\infty}=0.10$ are presented in Reference 18. The performance advantage of the smaller blowing slot is further demonstrated in Figure 14 which compares the lift curves for both blowing slots at NPR=1.50, to the no blowing case (NPR=1.00). The smaller blowing slot provides increased lift over the entire angle of attack range with $\mathrm{C} \mu=0.0068$, a $31 \%$ reduction in the value of $\mathrm{C}_{\mu}$ compared to the $\mathrm{h} / \mathrm{c}=0.0032$ configuration.

\begin{tabular}{|c|c|c|c|c|c|c|}
\hline & run & $\mathrm{M}_{\infty}$ & $\operatorname{Re}$ & NPR & $\mathrm{C}_{\mu}$ & $\mathrm{h} / \mathrm{c}$ \\
\hline & 11 & 0.20 & 10.05 & 1.00 & 0.000 & 0.0021 \\
\hline F--.. & 136 & 0.20 & 10.00 & 1.51 & 0.068 & 0.0021 \\
\hline 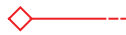 & 197 & 0.20 & 10.00 & 1.51 & 0.099 & 0.0032 \\
\hline
\end{tabular}
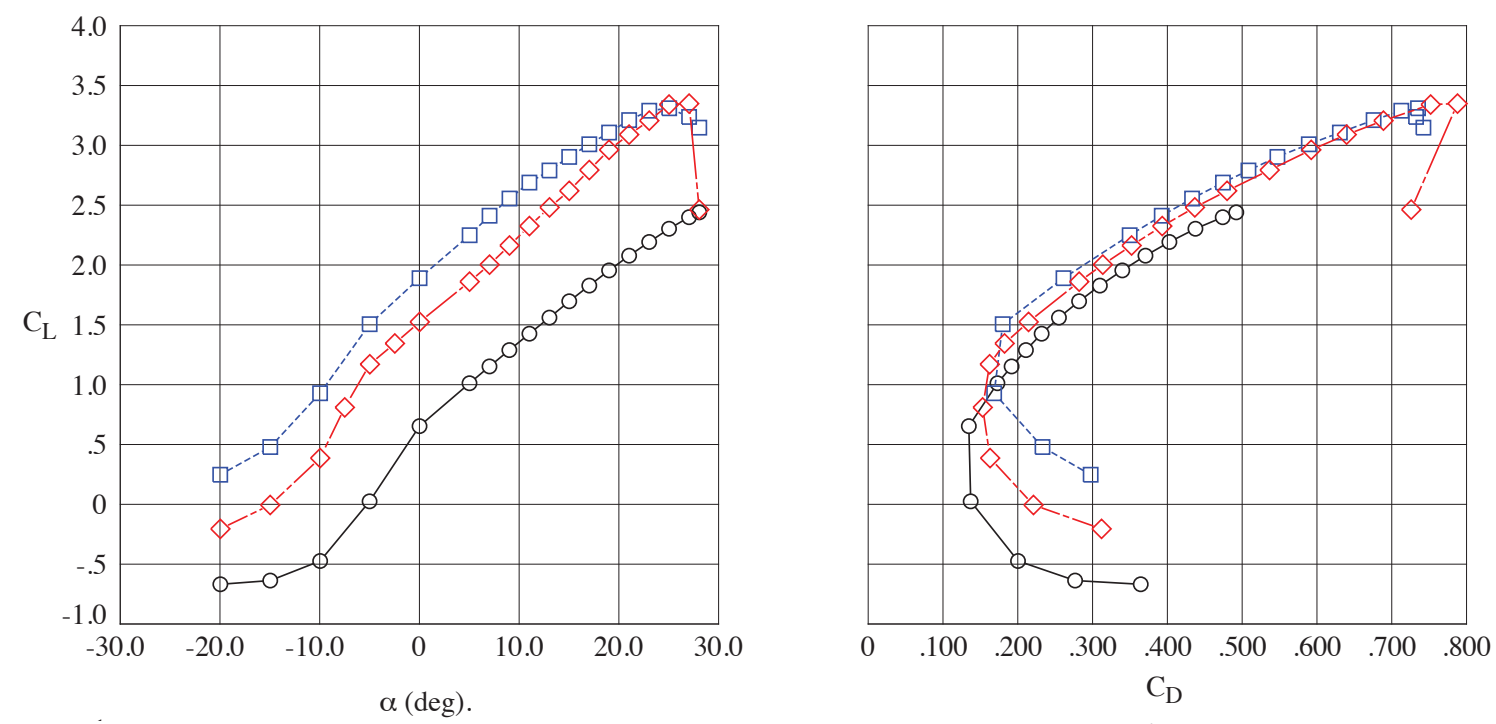

Figure 14: Effect of blowing slot $\mathrm{h} / \mathrm{c}$ ratio on the lift and drag coefficients for the $60^{\circ}$ flap $\left(M_{*}=0.20, R e=10 \times 10^{6}\right)$. 

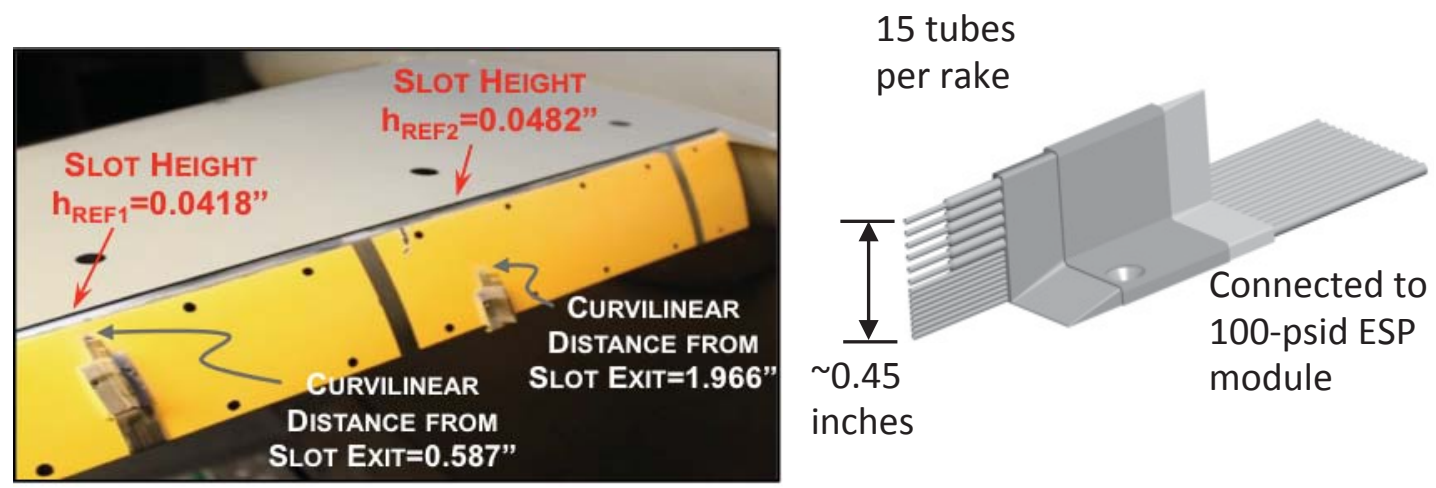

Figure 15: Miniature rake configuration for the $60^{\circ}$ flap, $\mathrm{h} / \mathrm{c}=0.0021$

A limited set of boundary layer profile data was obtained for the $\mathrm{h} / \mathrm{c}=0.0021$ configuration using miniature boundary layer rakes shown in Figure 15. The inboard rake is near the quarterspan location of the flap and located 0.65 flap chords downstream of the blowing slot, while the outboard rake is near mid span of the flap and 0.22 flap chords downstream of the blowing slot.

A sample of the measured profiles are shown in Figure 16 for various NPR values at $\mathrm{M}_{\infty}=0.20, \alpha$ $=0{ }^{\circ}$ and $\operatorname{Re}=10 \times 10^{6}$. Note that the rake height has been scaled based on the local blowing slot height at each location. The measurements indicate the flow remained attached for these conditions. Data was also obtained during several angle-of-attack sweeps at both NPR=1.00 and $\mathrm{NPR}=1.60$. The rakes were only installed for these limited runs, to avoid impacting the aerodynamic performance of the model. The data presented below do not have the rakes installed.

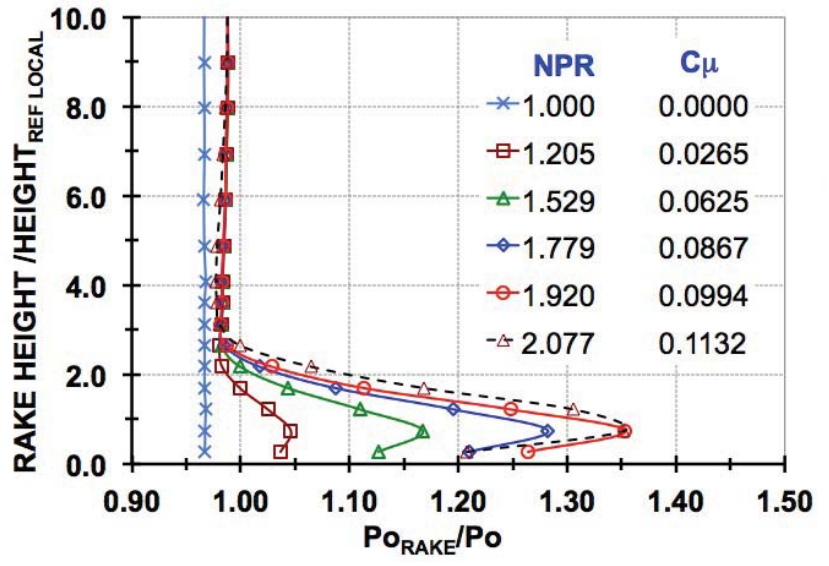

a) outboard rake

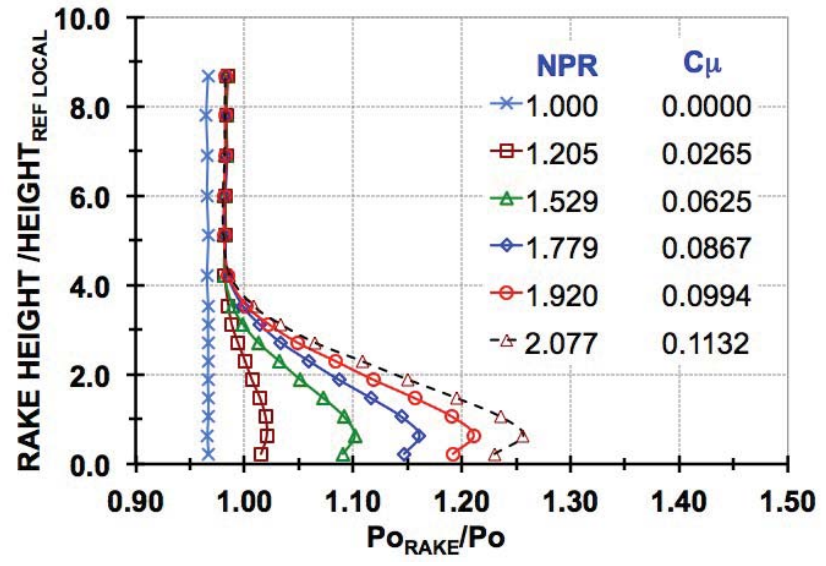

b) inboard rake

Figure 16: Total pressure profiles measured using the miniature rakes on the $60^{\circ}$ flap configuration, $\mathrm{h} / \mathrm{c}=0.0021$ $\left(\mathrm{M}_{s}=0.20, \alpha=0^{\circ}, \mathrm{Re}=10 \times 10^{6}\right)$. 
Figure 17 presents the lift and drag coefficient characteristics of the $h / c=0.0021$ blowing slot as the model is pitched in angle-of-attack for various blowing rates. Based on the NPR sweep data shown in Figure 13, NPR=1.22 represents the start of the super-circulation regime for the model. The surface pressure data indicated the flow remained attached until the stall angle was achieved. Further increases in the blowing resulted in increased lift, with the NPR $=1.80$ case only slightly outperforming the NPR=1.50 condition.

\begin{tabular}{|c|c|c|c|c|c|c|}
\hline & run & $\mathrm{M}_{\infty}$ & $\mathrm{Re}$ & NPR & $\mathrm{C}_{\mu}$ & $\mathrm{h} / \mathrm{c}$ \\
\hline & 111 & 0.20 & 10.05 & 1.00 & 0.000 & 0.0021 \\
\hline & 138 & 0.20 & 9.99 & 1.22 & 0.036 & 0.0021 \\
\hline --- & 136 & 0.20 & 10.00 & 1.51 & 0.068 & 0.0021 \\
\hline - & 137 & 0.20 & 10.01 & 1.81 & 0.097 & 0.0021 \\
\hline
\end{tabular}
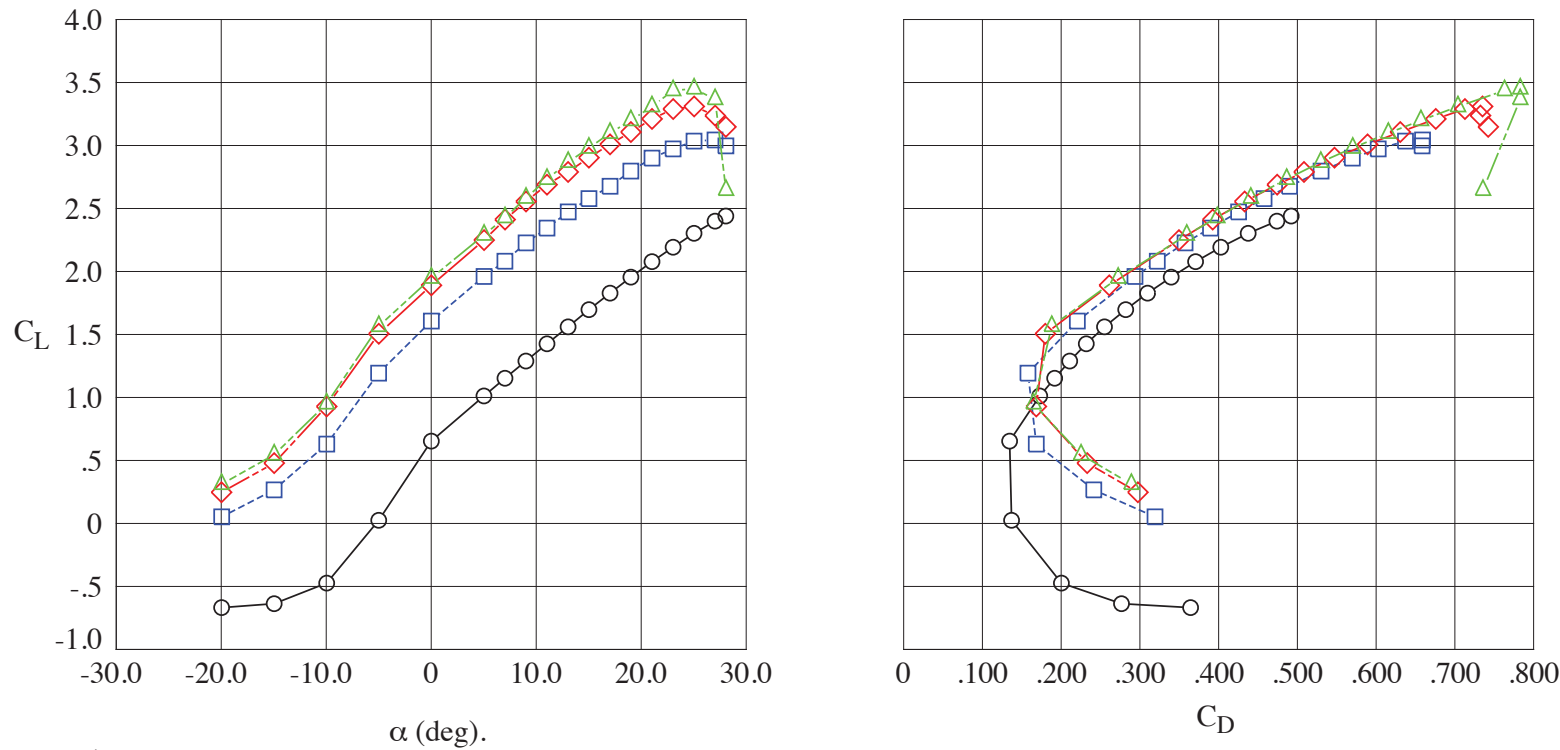

Figure 17: Effect of NPR on the performance of the $60^{\circ}$ flap, $\mathrm{h} / \mathrm{c}=0.0021\left(\mathrm{M}_{2}=0.20, \mathrm{Re}=10 \times 10^{6}\right)$. 
The surface pressure distributions at maximum lift are shown in Figure 18 for $\alpha=25^{\circ}$. Each span station plot has a legend that characterizes the local flow in each of the four independent plenums, and illustrates the level of spanwise uniformity of local NPR obtained for each blowing condition. For the blowing cases, the acceleration induced by the blowing slot at $\mathrm{x} / \mathrm{c}=0.85$ results in a pronounced suction peak, which exceeds the sonic condition at $\eta=0.20$ and 0.80 with $\mathrm{NPR}=1.80$ as denoted by the critical value of $\mathrm{C}_{\mathrm{p}}{ }^{*}$. Flow separation has begun to appear on the flap at $\eta=0.60$ with separation occurring near $\mathrm{x} / \mathrm{c}=0.90$. The wing pressures also indicate that the slat has a sonic flow region at $\eta=0.80$ for both blowing conditions.

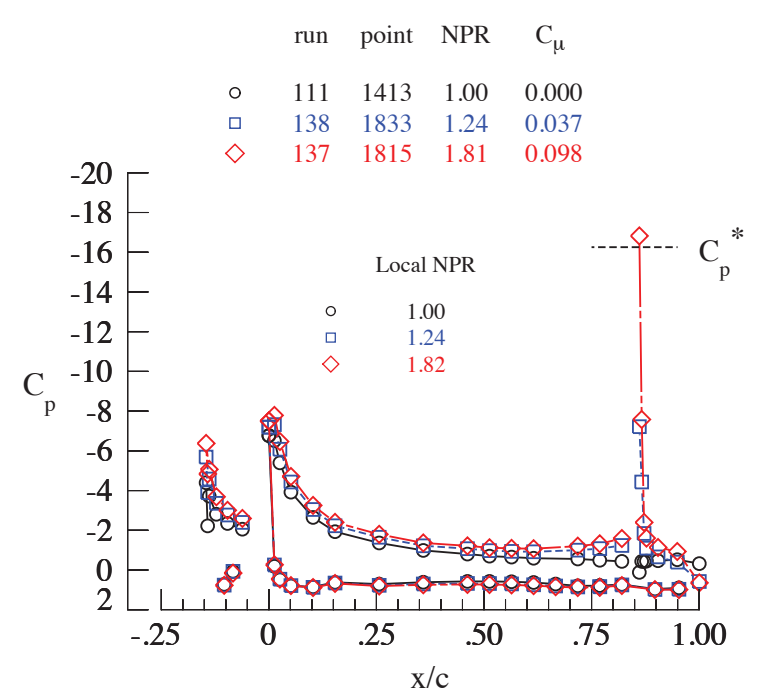

a) $\eta=0.20$

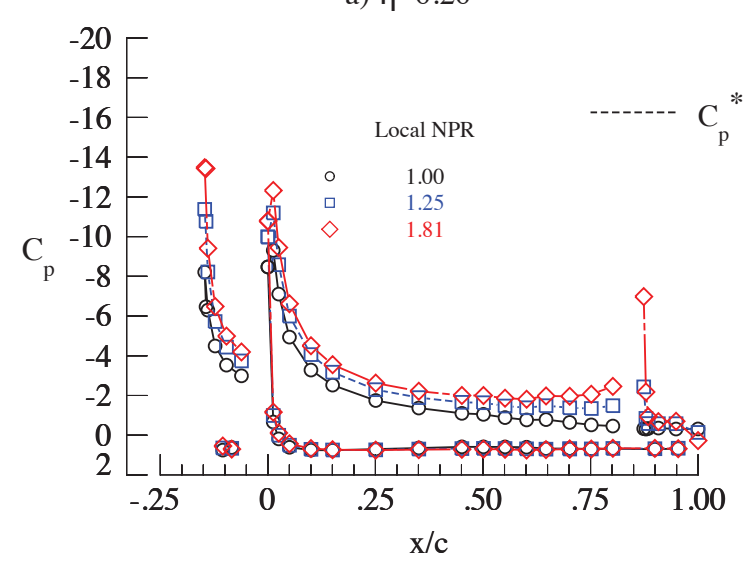

c) $\eta=0.60$

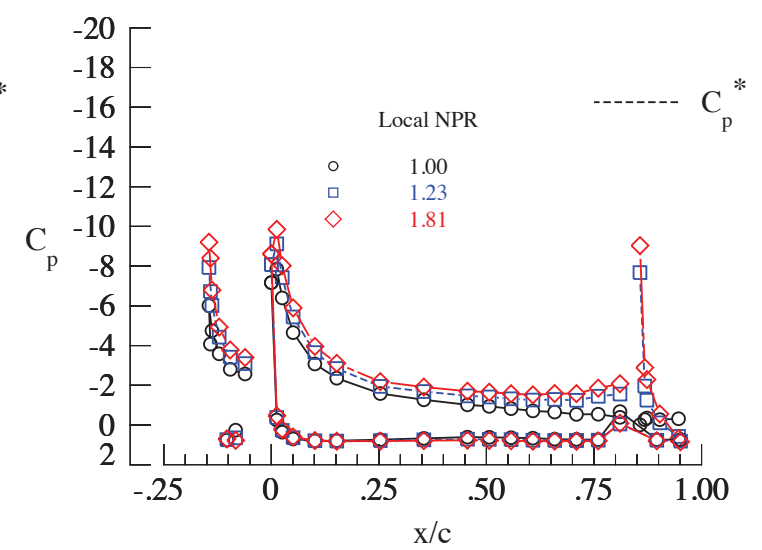

b) $\eta=0.40$

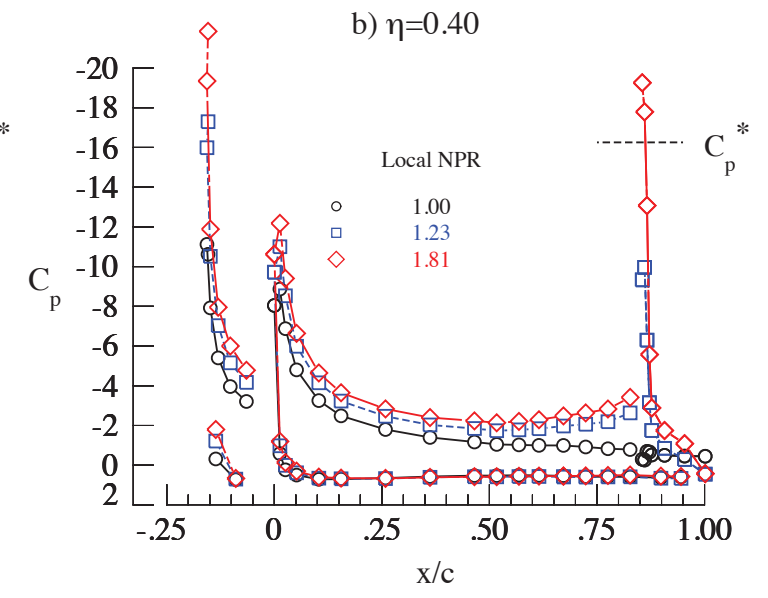

d) $\eta=0.80$

Figure 18: Effect of NPR on the wing pressure distributions of the $60^{\circ}$ flap, $h / c=0.0021\left(M_{s}=0.20, \alpha=25^{\circ}, \operatorname{Re}=10 \times 10^{6}\right)$. 


\section{B. Low-Speed High-Lift Testing, $30^{\circ}$ Flap}

Time constraints did not allow the $30^{\circ}$ flap to be evaluated during Test 195 but generous time was allotted during Test 213 to document this intermediate flap deflection. The non-dimensional blowing slot height was again set to be $\mathrm{h} / \mathrm{c}=0.0021$, but it should be noted this flap deflection required a unique set of shims as compared to the other flap deflections. Figure 19 compares a blowing rate sweep at $\alpha=0^{\circ}$ and $\operatorname{Re}=15 \times 10^{6}$ for both high-lift flap deflections. It should also be noted that the lowest blowing rate for the $30^{\circ}$ flap corresponds to a $C_{\mu}$ value of approximately 0.01 which correspond to the beginning of the super-circulation region. This pressure setting was the lowest pressure ratio (NPR 1.05) that could be uniformly supplied to all four plenums.

The super-circulation response of the $30^{\circ}$ flap to $\mathrm{C}_{\mu}$ is nearly linear, and the highest flow rate
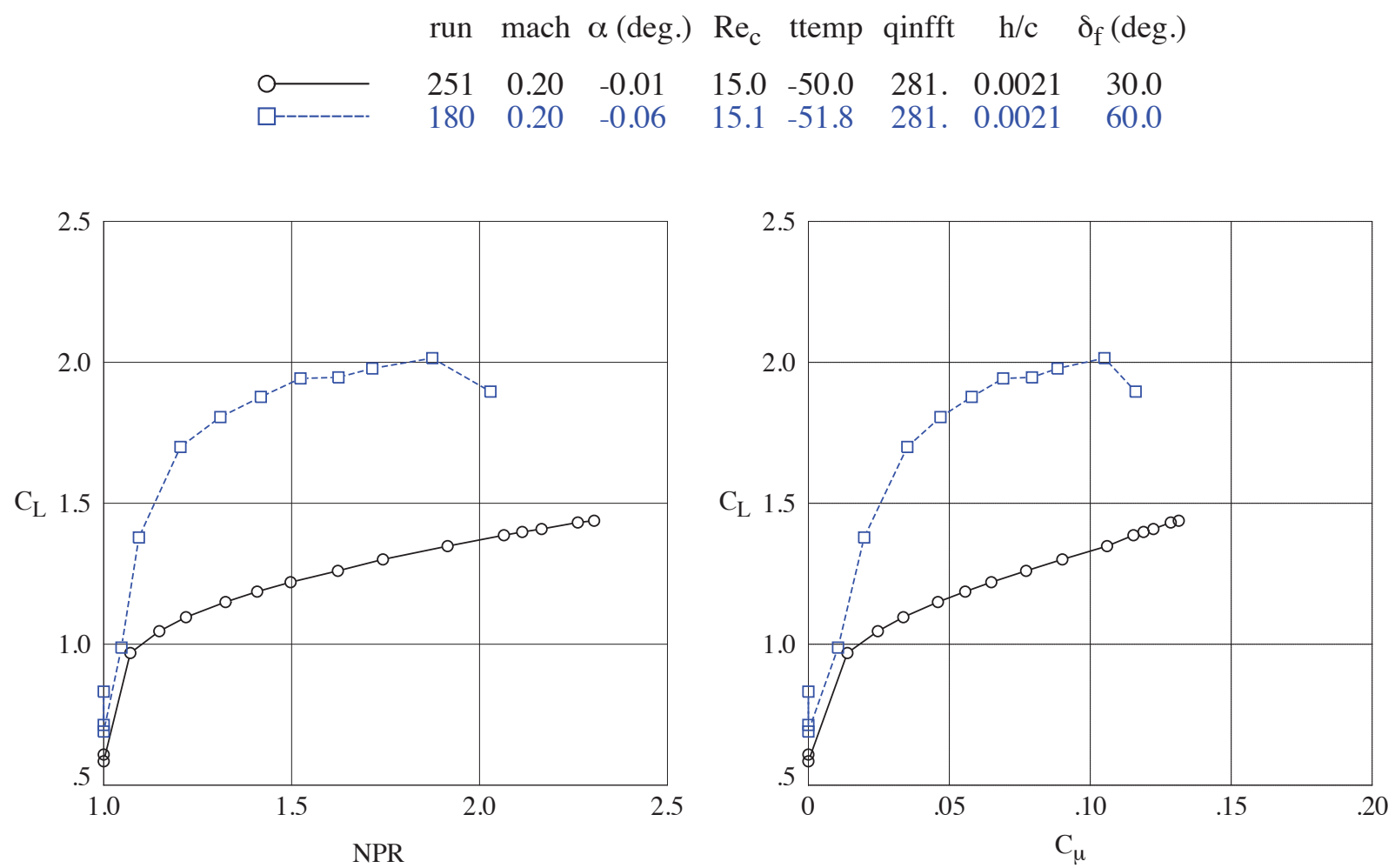

Figure 19: Effect of NPR on the performance of the $30^{\circ}$ and $60^{\circ}$ flaps, $h / c=0.0021\left(M_{s}=0.20, \alpha=0^{\circ}, \operatorname{Re}=15 \times 10^{6}\right)$.

represents $\mathrm{NPR}=2.30$, which was limited by the pressure safety limit dictated by the plenum cover plate. A family of lift and drag coefficient curves for the $30^{\circ}$ flap are shown in Figure 20 for $\mathrm{Re}=15 \times 10^{6}$. The linear response to $\mathrm{C}_{\mu}$ has been preserved across the angle-of-attack range, but the stall angle could not be determined due to a mechanical limitation of the angle-of-attack range implemented during the model installation. For this tunnel condition, the model safety system would not allow testing above $\alpha=25^{\circ}$ at NPR=1.80 due to exceeding the yawing moment limit of the wing structure. In contrast to the $60^{\circ}$ flap data (Figure 17), the $30^{\circ}$ flap configuration does recover a portion of the thrust from the blowing slot, note that the minimum drag approaches zero. 


\begin{tabular}{ccccccc} 
& run & $\mathrm{M}_{\infty}$ & $\mathrm{Re}$ & $\mathrm{NPR}$ & $\mathrm{C}_{\mu}$ & $\mathrm{h} / \mathrm{c}$ \\
\hdashline- & 249 & 0.20 & 15.02 & 1.00 & 0.000 & 0.0021 \\
$\square-------$ & 252 & 0.20 & 15.02 & 1.06 & 0.012 & 0.0021 \\
$\diamond$ & 253 & 0.20 & 15.00 & 1.21 & 0.032 & 0.0021 \\
$\triangle \square---$ & 254 & 0.20 & 15.00 & 1.52 & 0.067 & 0.0021 \\
$\square \square---$ & 255 & 0.20 & 14.99 & 1.80 & 0.095 & 0.0021
\end{tabular}
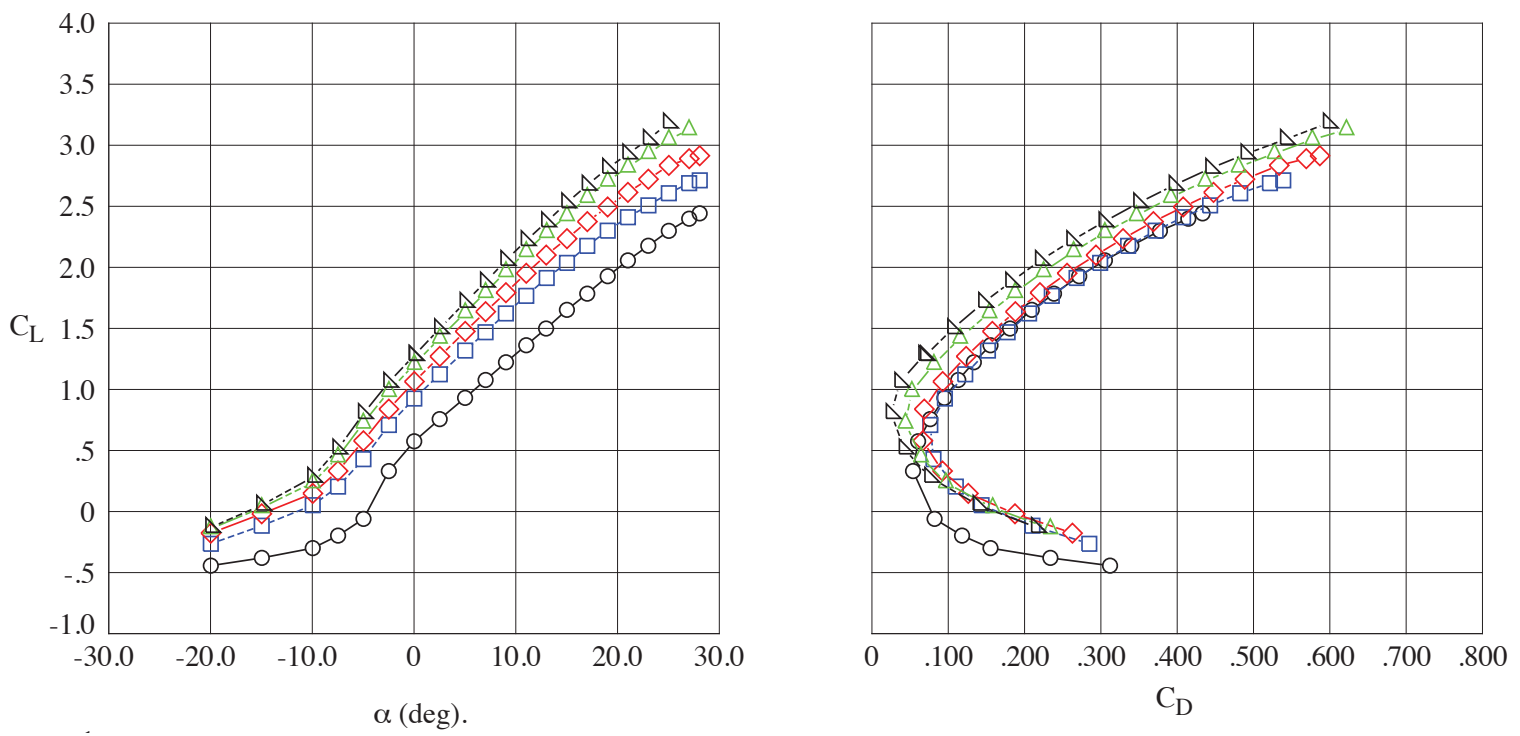

Figure 20: Effect of NPR on the performance of the $30^{\circ}$ flap, $h / c=0.0021\left(M_{s}=0.20, R e=15 \times 10^{6}\right)$.

\section{Transonic Cruise Testing}

To examine the effect of blowing at transonic conditions, numerous momentum sweeps were again performed at fixed angles-of-attack, at various combinations of Mach and Reynolds numbers. The modified BCRS discussed earlier in the paper was found to improve the thermal conditioning of the balance during the mild cryogenic operations, however it was not able to adequately maintain balance temperature stability during an entire shift of testing. The balance temperature distributions were closely monitored and data operations were halted when the balance was observed to drop to $90^{\circ} \mathrm{F}$. Due to the thermal mass of the balance system, it often took more than eight hours of downtime to return the balance to the desired operating temperature of $100^{\circ} \mathrm{F}$. The BCRS is currently being redesigned to significantly enhance the enthalpy transfer capability for transonic testing at the mild cryogenic conditions, and a demonstration wind tunnel test is in the planning stages. 


\begin{tabular}{ccccccccc} 
& run & $\mathrm{M}_{\infty}$ & $\mathrm{Re}$ & $\mathrm{T}_{\mathrm{o}}$ & $\mathrm{q}_{\infty}$ & $\mathrm{P}_{\infty}$ & NPR & test \\
\hdashline & 320 & 0.850 & 29.88 & -48.8 & 1996. & 27.23 & 1.00 & 213 \\
$\square------$ & 331 & 0.850 & 14.98 & 120.7 & 1596. & 21.80 & 1.00 & 213
\end{tabular}
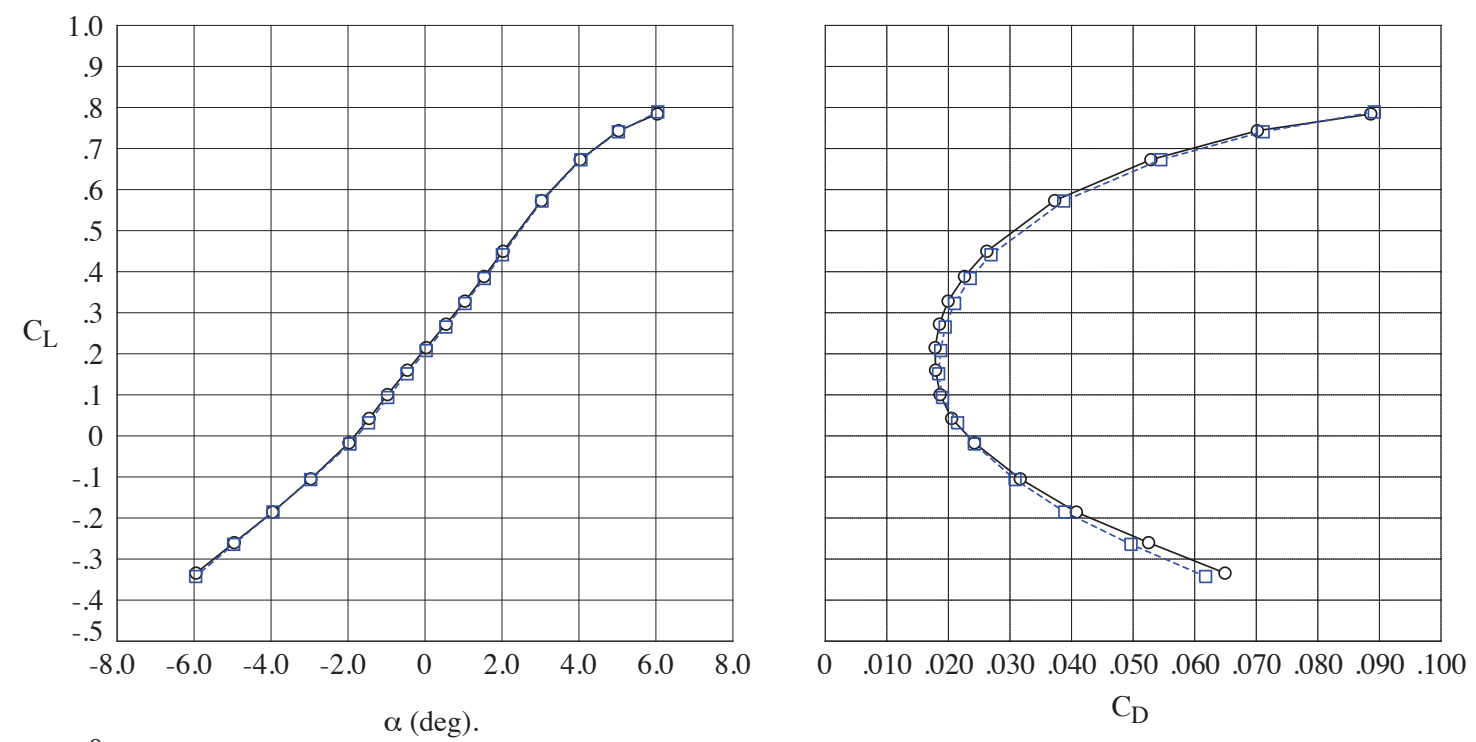

Figure 21: Effect of tunnel temperature on lift and drag coefficient data from Test $213\left(\mathrm{M}_{*}=0.85, \mathrm{C}_{\mu}=0.0\right)$.

Although the BCRS had an adverse effect on testing productivity, the resulting data shows a significant improvement in repeatability as compared to Test 195, particularly at the mild cryogenic tunnel conditions of $-50^{\circ} \mathrm{F}$. An example of this improvement is seen in Figure 21 where the lift and drag coefficient curves for a warm and mild cryogenic run are compared and found to have the same shapes, in sharp contrast to the poor performance obtained in Test 195 (Figure 4). The level of drag repeatability observed in Test 213 is shown in Figure 22 for $\mathrm{M}_{\infty}=0.85$ and $\mathrm{Re}=30 \times 10^{6}$ for several non-blowing cases over a two day period. The $2 \sigma$ variation in the drag coefficient is 0.00099 , which is greater than the value based on the system-level balance pressure tare calibration shown previously in Table 1 for these conditions. For back-to-back repeats, the $2 \sigma$ variation in the drag coefficient was typically 0.0005 . The repeatability analysis did show a strong correlation to the undesirable balance temperature gradients still present with the current BCRS configuration. As a result, the overall $2 \sigma$ values for data repeatability in the transonic portion of the test are: $C_{L} \pm 0.0030, C_{D} \pm 0.0010$. 


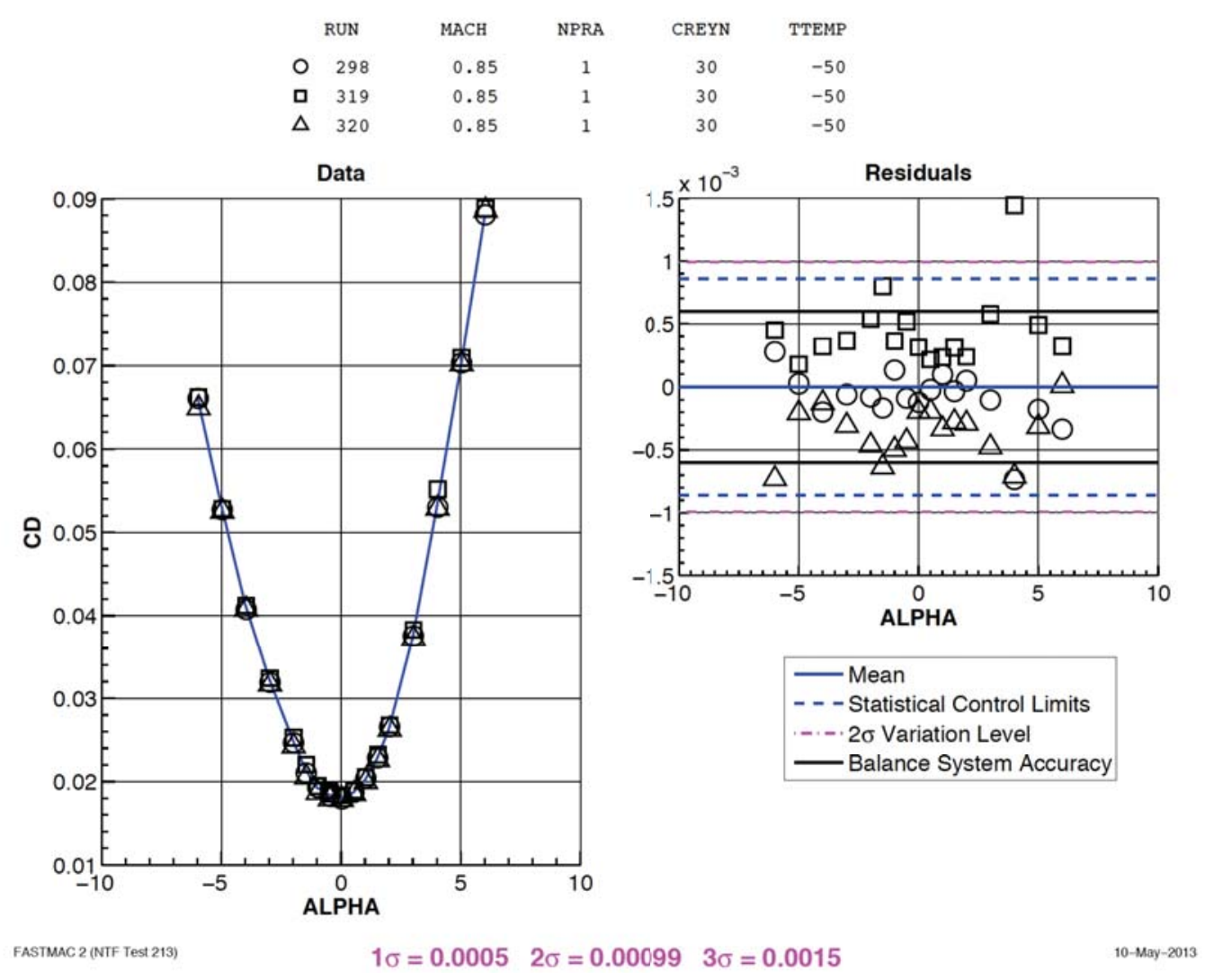

Figure 22: Example of drag coefficient repeatability from Test $213\left(\mathrm{M}_{\alpha}=0.85, \mathrm{C}_{\mu}=0.0\right)$

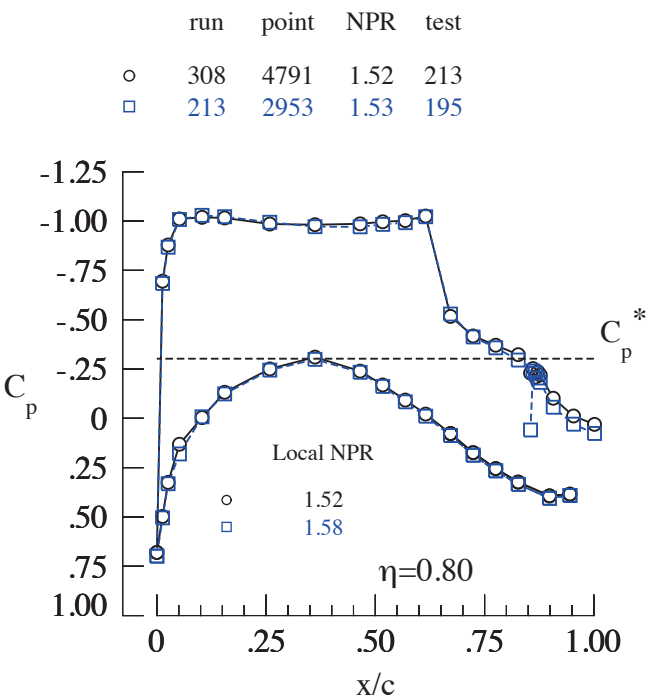

Figure 23: Test-to-test comparison of wing pressure coefficient data $\left(M_{x}=0.85, \alpha=3^{\circ}, \operatorname{Re}=30 \times 10^{6}\right)$.
The data obtained in Test 213 again demonstrated that the circulation control blowing through the slot located at $85 \%$ chord is effective in re-attaching the flow on the aft portion of the wing at off-design conditions where shockinduced flow separation occurred. Due to the problems with the balance data from Test 195 the test-to-test comparison will be made using the wing pressures. Figure 23 compares a representative row of the wing pressures at $\mathrm{M}_{\infty}=0.85, \alpha=3^{\circ}, \mathrm{Re}=30 \times 10^{6}$ with $\mathrm{NPR}=1.50$. This is an off-design condition in lift coefficient and the flow has been reattached. The test-to-test repeatability of the flow physics is excellent with similar agreement observed at the other test conditions, and NPR values.

One important result from Test 195 was that the circulation control blowing had an effect on the wing when the flow was fully attached ${ }^{6}$, which is examined in more detail with the new data from Test 213. Figure 24 examines the effect of NPR on the wing pressures near the design 
point of the wing $\left(\mathrm{M}_{\infty}=0.85, \alpha=3^{\circ}, \mathrm{Re}=30 \times 10^{6}\right)$. Blowing rates below NPR=1.70 were again observed to move the shockwave forward, due to the localized lower Mach number region created at the blowing slot. The NPR $=1.70$ condition restores the shock position and replicates the no-blowing pressure distribution quite well. As the blowing rate increases, the shock moves aft on the two outboard stations, and all locations indicate accelerated flow downstream of the blowing slot, increasing the lift coefficient.

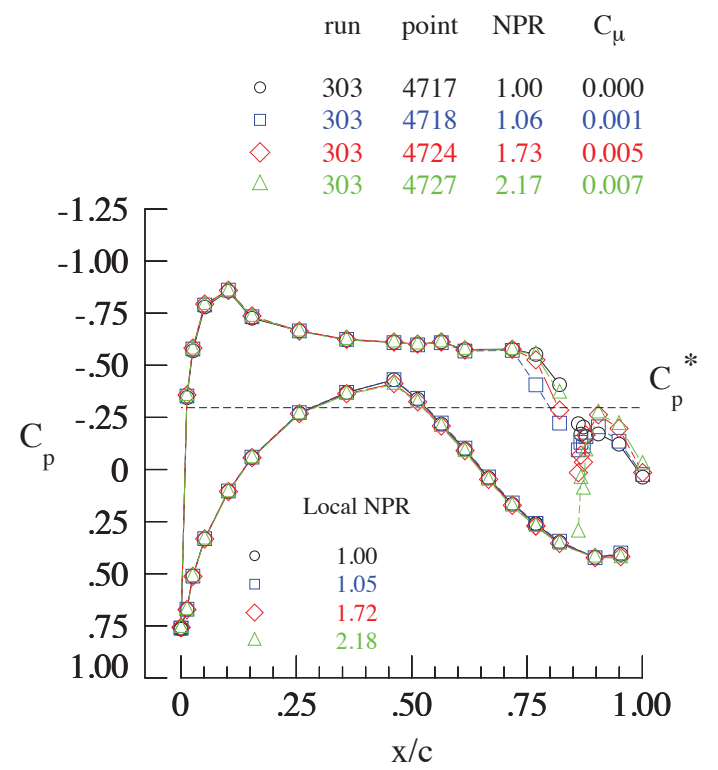

a) $\eta=0.20$

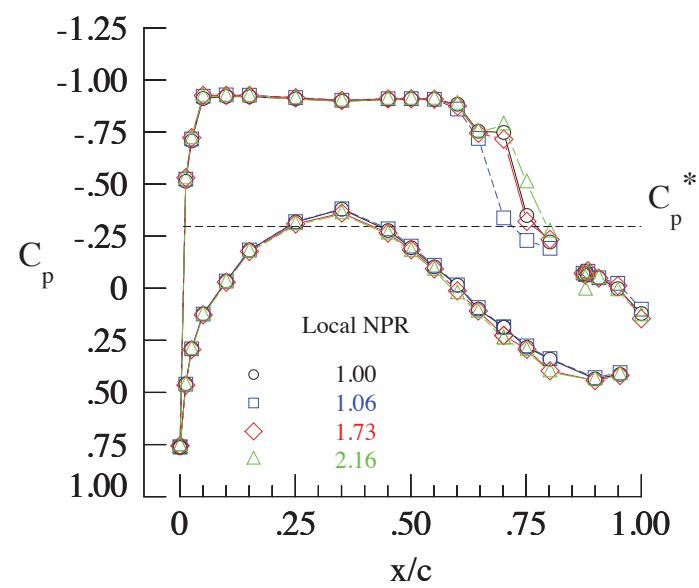

c) $\eta=0.60$

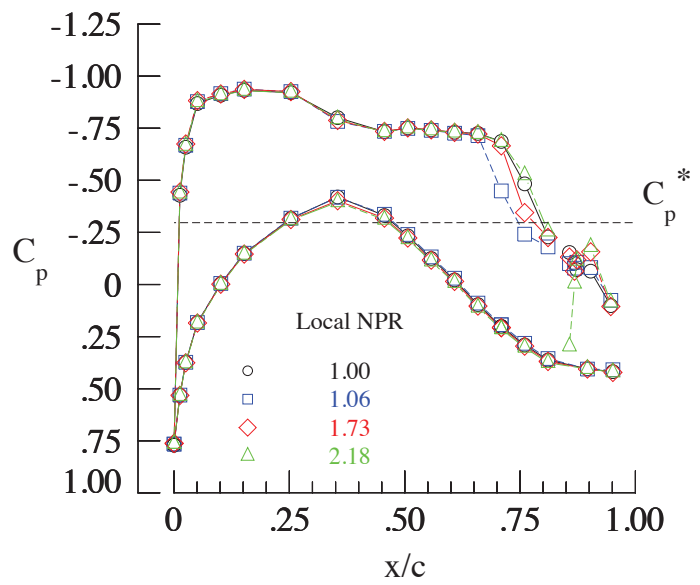

b) $\eta=0.40$

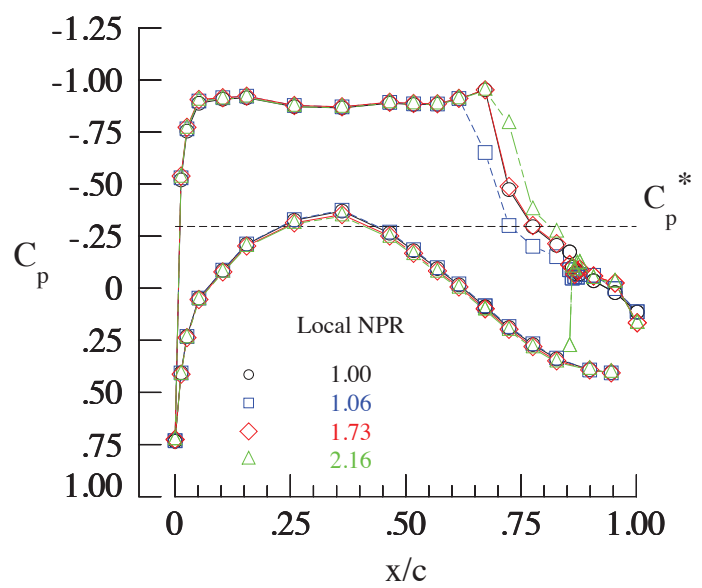

d) $\eta=0.80$

Figure 24: Effect of NPR on attached-flow wing pressure coefficient data $\left(M_{2}=0.85, \alpha=3^{\circ}, \operatorname{Re}=30 \times 10^{6}\right)$. 
The ability of the circulation control to reattach the flow over the wing at off-design conditions was again examined in detail. The previous paper focused on off-design conditions at $\mathrm{M}_{\infty}=0.85$ (Ref 6) while the present discussion will focus on the off-design condition of elevated Mach number. Figure 25 presents the effect of NPR on the wing pressures at $\mathrm{M}_{\infty}=0.88, \alpha=3^{\circ}, \mathrm{Re}=30 \times 10^{6}$. The no-blowing case has flow separation present on the two

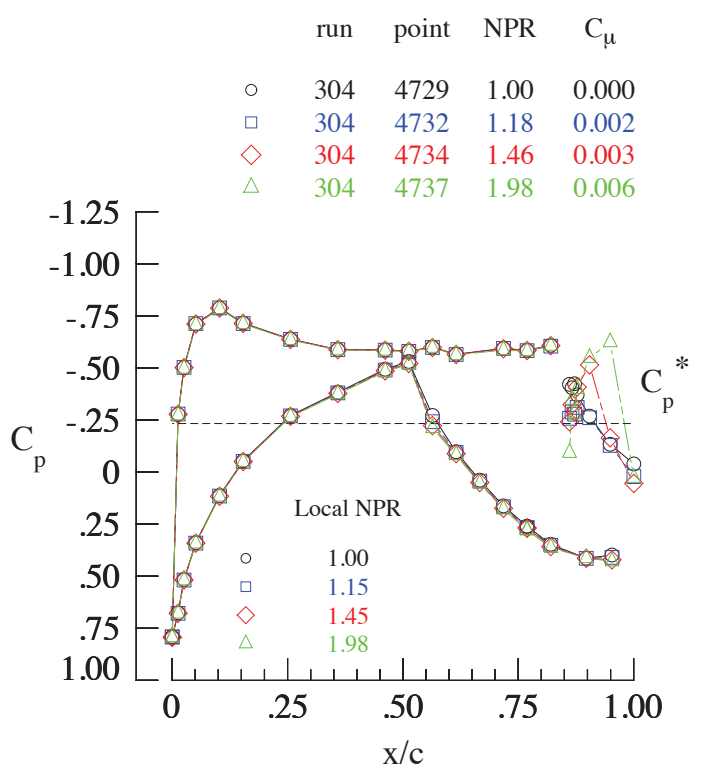

a) $\eta=0.20$

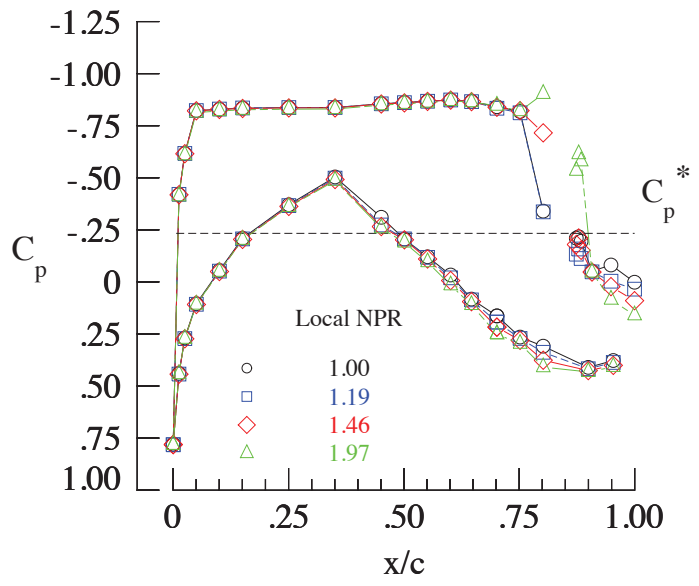

c) $\eta=0.60$

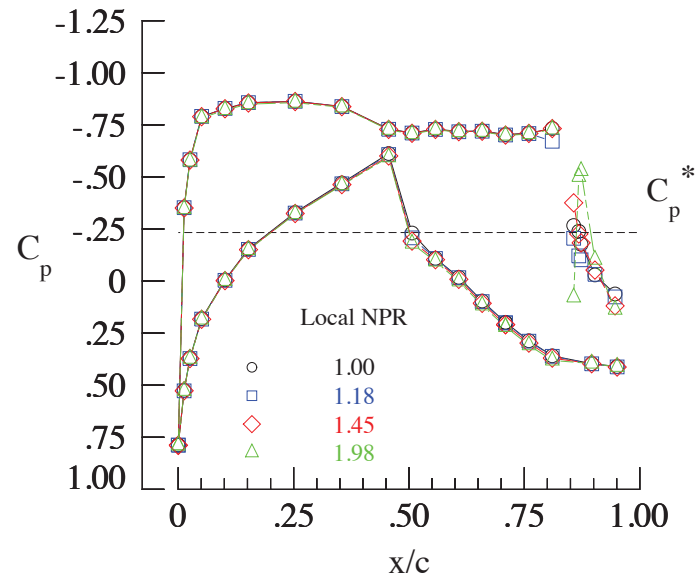

b) $\eta=0.40$

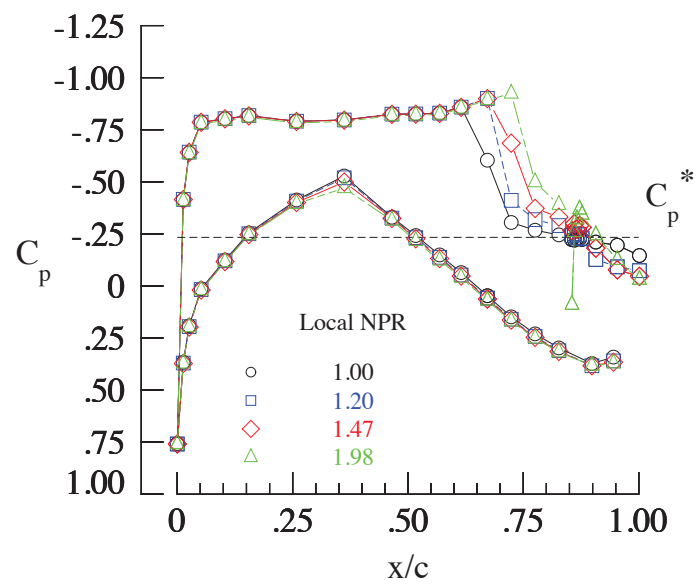

d) $\eta=0.80$

Figure 25: Effect of NPR on off-design wing pressure coefficient data $\left(\mathrm{M}_{s}=0.88, \alpha=3^{\circ}, \operatorname{Re}=30 \times 10^{6}\right)$.

outboard stations. The NPR $=1.18$ condition reattaches the flow, and moves the shock aft $5 \%$ chord at $\eta=0.80$. Note that the shockwave strength did not increase, and a drag reduction is inferred. The two higher blowing conditions continue to move the shock aft, however a double shock pattern develops on the inboard station of the wing. CFD studies were conducted to 
develop a tailored spanwise blowing distribution to alleviate the double shock formation on the wing, which will be discussed later.

The net effect of the circulation control blowing on the lift coefficient at both Mach numbers discussed above is shown in Figure 26 for the various Reynolds numbers tested. For each NPR sweep, the no-blowing $(\mathrm{NPR}=1.00)$ lift coefficient has been subtracted to minimize the aeroelastic differences. Recall that the $\mathrm{M}_{\infty}=0.85$ pressure distributions shown in Fig 24 indicate attached flow over the wing, and as a result a distinct Reynolds number trend is not observed in the lift coefficient variation with NPR. The $\mathrm{M}_{\infty}=0.88$ condition however has substantial flow separation as indicated in the non-blowing pressure distributions in Figure 25, and as a result the lift coefficient variation with NPR does suggest a Reynolds number

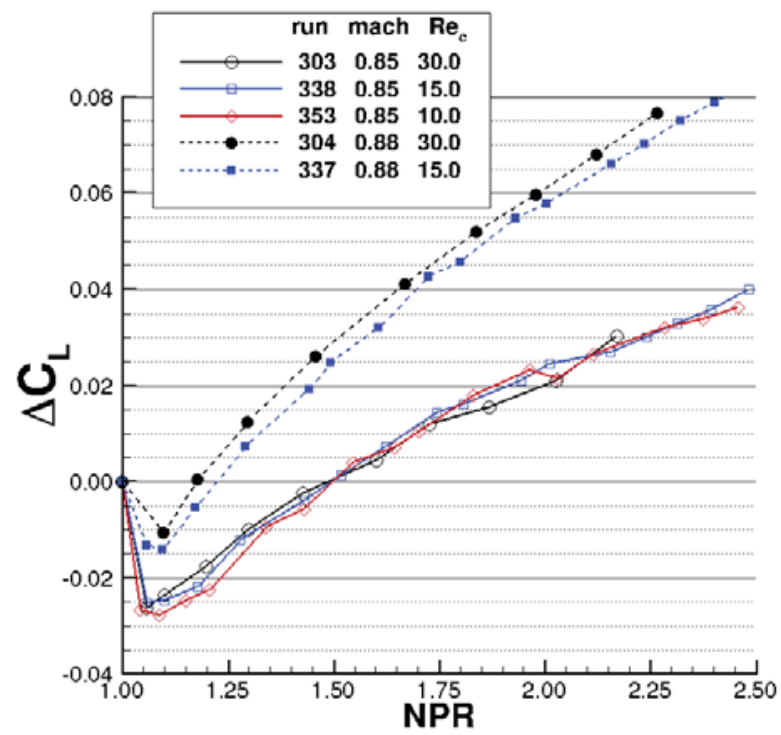

Figure 26: Effect of NPR on lift coefficient at various flow conditions $\left(\alpha=3^{\circ}\right)$. effect. Careful consideration should be given to this, as the difference in the lift increment at a given NPR is only slightly larger than the $2 \sigma$ repeatability value of 0.0030 .

The final data to be presented is for the tailored spanwise blowing study developed using CFD. As discussed above for the $\mathrm{M}_{\infty}=0.88$ blowing sweep at $\alpha=3^{\circ}$ (Figure 25), the higher NPR values created a double shock pattern at $\eta=0.20$. CFD runs were performed at these same conditions after this same behavior was observed in the Test 195 data. The blowing rate was varied for each plenum, while maintaining a minimum threshold of blowing on the outboard portion of the wing to maintain attached flow. The experimental results are shown in Figure 27

for $M_{\infty}=0.88, \alpha=3^{\circ}, \operatorname{Re}=15 \times 10^{6}$. The tailored blowing result, point 5436, has the local NPR in the inboard plenum set to 1.15 , which increases across the span to a value of 1.76 in the outboard plenum. The resultant average NPR of the system is 1.46. The tailored blowing avoids the double shock formation at the inboard location, reattaches the flow field, and produces nearly the same pressure distribution at $\eta=0.80$ as the uniform NPR=1.80 condition. The tailored blowing condition results in a $40 \%$ reduction in the value of $\mathrm{C}_{\mu}$. 


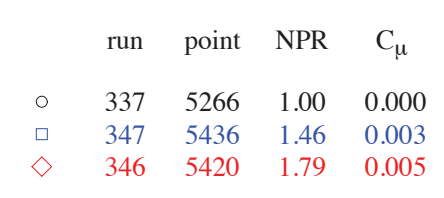

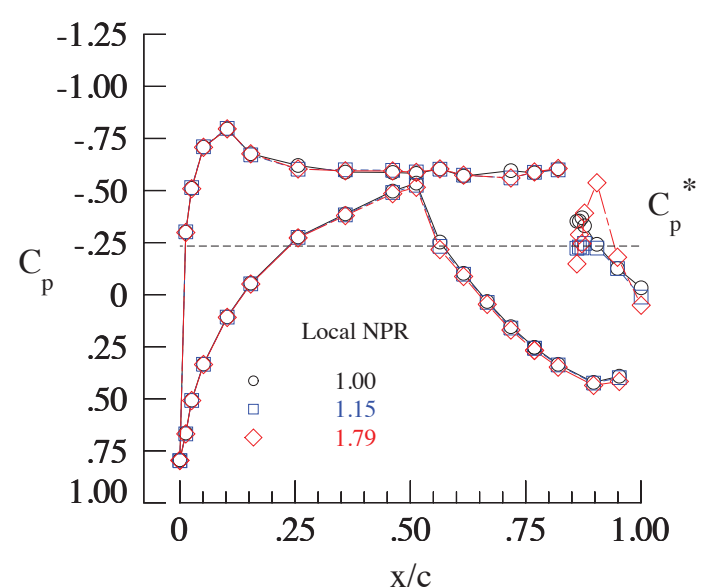

a) $\eta=0.20$

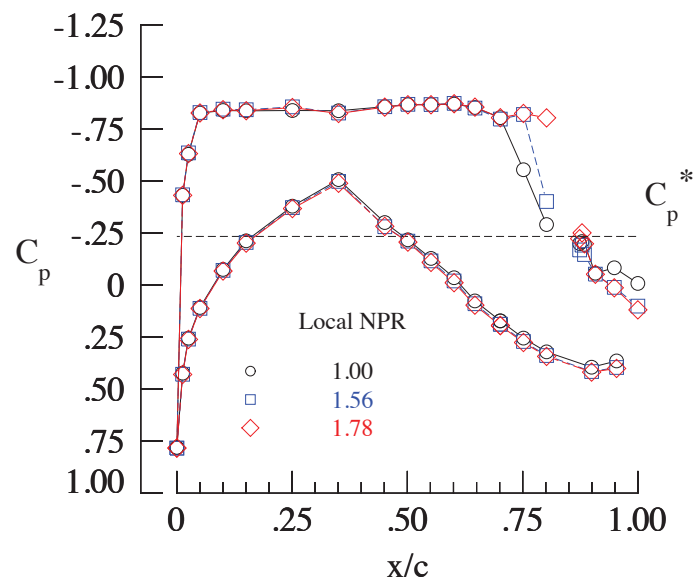

c) $\eta=0.60$

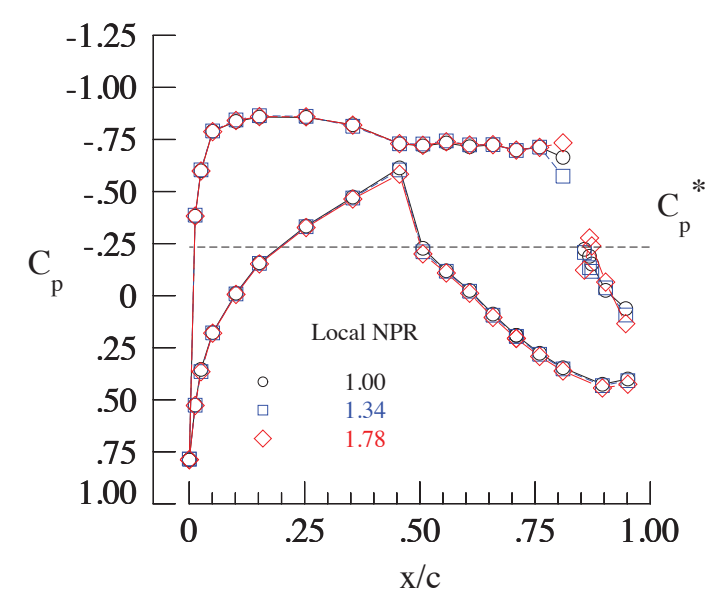

b) $\eta=0.40$

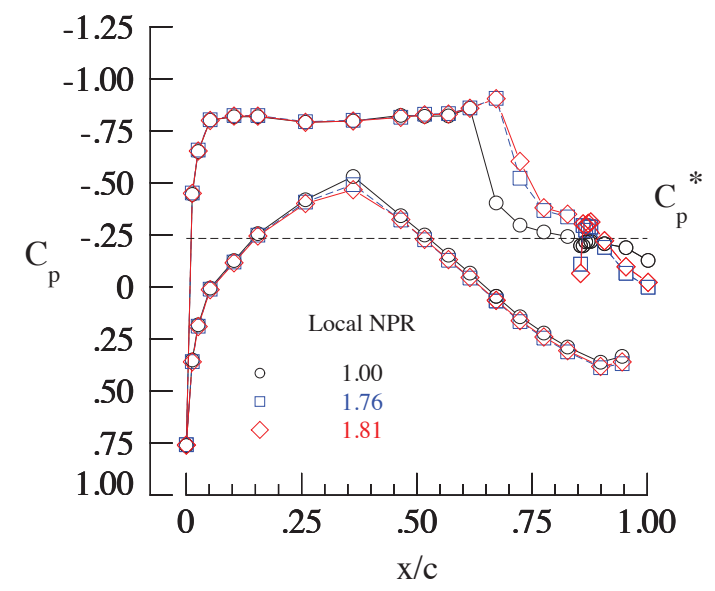

d) $\eta=0.80$

Figure 27: Effect of tailored spanwise blowing on off-design wing pressure coefficient data $\left(\mathrm{M}_{\alpha}=0.88, \alpha=3^{\circ}, \mathrm{Re}=15 \times 10^{6}\right)$.

\section{Conclusions}

A second wind tunnel test of the FAST-MAC circulation control model was recently completed in the National Transonic Facility at the NASA Langley Research Center. The model was equipped with four onboard flow control valves allowing independent control of the circulation control plenums, which were directed over a $15 \%$ chord simple-hinged flap. The model was configured for low-speed high-lift testing with flap deflections of 30 and 60 degrees, along with the transonic cruise configuration with zero degree flap deflection. Testing was again conducted over a wide range of conditions, Mach numbers up to 0.88 and chord Reynolds numbers of 30 million. The test made significant contributions to the continued development of a public database for CFD code validation for circulation control techniques, and provides unique insights into the Reynolds number scaling effects for this type of active flow control. 
The test-to-test repeatability of the flow physics was shown to be excellent, as demonstrated by wing pressure comparisons. The following conclusions can be drawn from the results that have been presented.

Several improvements were made to the force and moment balance system based on the continued analysis of the first test of the model. The first improvement was the development of the PIP to replace the concentric convoluted bellows, which bridges the high-pressure air supply across the balance to the wind tunnel model. A new system-level static pressure tare calibration was performed for the balance, which demonstrated significant improvements in the balance repeatability estimates. The observed improvements in the axial-force and normal-force components, compared to the bellows system was $19.7 \%$ and $46.9 \%$ respectively.

The second key improvement to the force and moment measurement system was the BCRS that provides convective heating to the balance-housing cavity. The data from the first test had poor repeatability of the transonic balance data due to balance temperature drifts at mild cryogenic tunnel conditions. The improved BCRS was found to significantly improve the transonic drag repeatability, to a \pm 10 drag count level, but unacceptable temperature gradients were still present on the balance, indicating further improvements are still required.

The low-speed high-lift testing included a new blowing slot-height study for the 60-degree flap configuration. Reducing the slot height to chord ratio from $\mathrm{h} / \mathrm{c}=0.0032$ to 0.0021 increased the circulation control induced lift increment by $28.75 \%$ at zero degrees angle-of-attack. The smaller slot height was shown to develop the same maximum lift coefficient at stall, but with a $31 \%$ reduction in the required mass flow. The performance of the new 30-degree flap was documented, and found to have a nearly linear response to the non-dimensional blowing coefficient. In contrast to the 60-degree flap, the 30-degree flap was observed to recover a portion of the thrust from the circulation control blowing slot.

In the transonic regime the circulation control was again shown to be effective in altering the flow over the wing. For attached flow conditions at $\mathrm{M}_{\infty}=0.85$, the blowing increased the lift and moved the shockwave aft on the wing, without changing the strength of the shockwave. The lift increments due to the blowing did not show a discernable trend with Reynolds number.

At the off-design conditions at $\mathrm{M}_{\infty}=0.88$, the blowing was effective in re-attaching the shockinduced flow separation, and moved the shockwave aft more than $5 \%$ chord with no increase in shockwave strength. The lift increment due to blowing at these off-design conditions did suggest a Reynolds number effect, however it was only slightly larger than the $2 \sigma$ repeatability value. Lastly, a new tailored spanwise blowing technique developed using CFD analysis was demonstrated that was still effective in re-attaching the separated flow, but reduced the required mass flow by $40 \%$. Although the wing pressures suggest the circulation control blowing did result in tangible drag reductions, the thrust removal strategy has not been validated, and work continues to document the impact of the circulation control blowing parameters on the configuration drag levels. 


\section{Acknowledgements}

The research has been supported by the Fixed Wing project. Special thanks are given to Ruben Delrosario, Mike Rogers, Richard Wahls, and Susan Wilz for their continued support and enthusiasm. The successful second test of the FAST-MAC model could not have been accomplished without the dedication, technical expertise, and energy of the entire staff at the National Transonic Facility. Special appreciation is extended to Tom Hall for his expertise in building the miniature boundary layer rakes, and to Mark Cagle for his excellent oversight of the design and fabrication of the upgrades for the FAST-MAC model. Special gratitude is extended to the staff of both the National Force Measurement Technology Capability Office at NASA, and Modern Machine and Tool Inc., for their continued efforts in supporting the development of the NTF-117S semi-span balance system.

\section{References}

${ }^{1}$ Zeune, C.H., "An Overview of the Air Force's Speed Agile Concept Demonstration Program," AIAA Paper 2013-1097, January 2013.

${ }^{2}$ Barberie, F.J., Wick, A.T., Hooker, J.R., Zeune, C.H., "Low Speed Powered Lift Testing of a Transonic Cruise Efficient STOL Military Transport,", AIAA Paper 2013-1099, January 2013.

${ }^{3}$ Harrison, N.A., Vassberg, J.C., DeHann, M.A., Gea, L.M., "The Design and Test of a Swept Wing Upper Surface Blowing (USB) Concept,” AIAA paper 2013-1102, January 2013.

${ }^{4}$ Collins, S. W., Westra, B. W., Lin, J. C., Jones, G. S., and Zeune, C. H., "Wind Tunnel Testing of Powered Lift, All-Wing STOL Model," RAeS-566-5A3, presented at the 2008 International Powered Lift Conference, London, UK, July 2008.

5 Englar, R. J., "Development of the A-6 Circulation Control Wing Flight Demonstrator Configuration,” DTNSRDC Report ASED-79/01, January, 1979.

6 Milholen, W.E., Jones, G.S., Chan, D.T., and Goodliff, S.L., "High-Reynolds Number Circulation Control Testing the National Transonic Facility (Invited)", AIAA paper 2012-0103, January 2012.

${ }^{7}$ Rogers, E.O., and Donnelly, M.J., "Characteristics of a Dual-Slotted Circulation Control Wing of Low Aspect Ratio Intended for Naval Hydrodynamic Applications," AIAA Paper 2004-1244, January 2004.

8 Jones, G.S, Lin., J.C., Allan, B.G., Milholen II, W.E., Rumsey, C.L., and Swanson, R.C., "Overview of CFD Validation Experiments for Circulation Control Applications at NASA", International Powered Lift Conference, Royal Aeronautical Society, London, July 2008. 
9 Englar, R.J., Jones, G.S., Allan, B.G., and Lin, J.C., "2-D Circulation Control Airfoil Benchmark Experiments Intended for CFD Code Validation," AIAA Paper 2009-0902, January 2009.

${ }^{10}$ Swanson, R.C. and Rumsey, C.L., "Numerical Issues for Circulation Control Calculations," AIAA Paper 2006-3008, June 2006.

${ }^{11}$ Pfingsten, K.C and Radespiel, R., "Experimental and Numerical Investigation of a Circulation Control Airfoil", AIAA Paper 2009-533, January 2009.

${ }^{12}$ Wetzel, D., Griffin, J., Liu, F., and Cattafesta, L., "An Experimental Study of Circulation Control on an Elliptic Airfoil”, AIAA Paper 2009-4280, June 2009.

${ }^{13}$ Milholen II, W.E., Jones, G.S., and Cagle, C.M., "NASA High-Reynolds Number Circulation Control Research - Overview of CFD and Planned Experiments (Invited)", AIAA Paper 2010344, January 2010.

${ }^{14}$ Englar, R. J., Smith, M. J., Kelley, S. M., and Rover, R. C. III, “Application of Circulation Control Technology to Advanced Subsonic Transport Aircraft, Part I: Airfoil Development," AIAA Paper No. 93- 0644, AIAA Journal of Aircraft, Vol. 31, No. 5, pp. 1160-1168, Sept-Oct. 1994.

15 Englar, R.J., "Two- Dimensional Transonic Wind Tunnel Tests of Three 15-Percent -Thick Circulation Control Airfoils," Naval Ship R\&D Center Technical Note AL-182, AD 882-075, December 1970.

16 Jones, G.S., Yao, C., Allan, B.G., "Experimental Investigation of a 2D Supercritical Circulation-Control Airfoil Using Particle Image Velocimetry," AIAA 2006-3009, June 2006.

${ }^{17}$ Englar, R.J., Williams, R.M., "Test Techniques for High Lift, Two-Dimensional Airfoils with Boundary Layer and Circulation Control for Applications to Rotary Wing Aircraft", Canadian Aeronautics and Space Journal, Vol.19, No.3, March 1973.

18 Jones, G.S., Milholen II, W.E., Chan, D.T., Melton, L.P., Anders, S.G., Allan., B.G., Carter, M.B., Capone, F.J., and Goodliff, S.L., "Development of the Circulation Control Flow Scheme used in the NTF Semi-Span Model", to be presented at the $43^{\text {rd }}$ AIAA Fluid Dynamics Conference, San Diego, June 2013.

${ }^{19}$ Gatlin, G.M, Tomek, W.G., Payne, F.M., and Griffiths, R.C., "Recent Improvements in SemiSpan Testing at the National Transonic Facility (Invited)", AIAA Paper 2006-508, January 2006.

${ }^{20}$ Lynn, K.C., "Development of the NTF-117S Semi-Span Balance", AIAA Paper 2010-4542, June 2010. 
${ }^{21}$ Jones, G.S., Milholen II, W.E., and Goodliff, S.L., "Development of the Dual Aerodynamic Nozzle Model for the NTF Semi-Span Model Support System", AIAA Paper 2011-3170, June 2011.

${ }^{22}$ Lynn, K.C., Rhew, R.D., Acheson, M.J., Jones, G.S., Milholen, W.E., Goodliff, S.L., "HighReynolds Number Active Blowing Semi-Span Measurement System Development," AIAA Paper 2012-3318, June 2012. 